\title{
SOBRE EL CARAMBOLO: UN HÍPPOS SAGRADO DEL SANTUARIO IV Y SU CONTEXTO ARQUEOLÓGICO
}

\author{
JOSÉ LUIS ESCACENA CARRASCO \\ Universidad de Sevilla \\ ÁLVARO FERNÁNDEZ FLORES, ARACELI RODRÍGUEZ AZOGUE \\ Arqueología y Gestión S.L.L.
}

\section{RESUMEN}

Se estudia una reproducción en cerámica de un navío encontrada en el Carambolo (Camas, Sevilla). Dicho objeto se suma a otros elementos singulares que caracterizan a este enclave, y refuerza la hipótesis de que el complejo del Carambolo pudo ser un santuario fenicio.

\section{SUMMARY}

This paper studies a replica in pot of a boat found at the Carambolo (Camas, Seville). This object joins other known singular and characteristic elements of this site, and reinforces the hypothesis that the compound of the Carambolo would have been a Phoenician sanctuary.

PALABRAS CLAVE: Fenicios, barco, santuario.

KEY WORDS: Phoenicians, ship, sanctuary.

\section{EL YACIMIENTO: UN POCO DE HISTORIO- GRAFÍA}

La literatura arqueológica sobre el Carambolo ha insistido en la presencia en ese sitio de un poblado tartésico de fondos de cabaña, es decir, de un asentamiento indígena fundado antes de la colonización fenicia. Las dataciones otorgadas a sus materiales más representativos habrían venido a consolidar esta hipótesis (Castro y otros 1996: 198). Pero ésta no ha sido la única interpretación barajada, ya que desde su descubrimiento se insinuó la existencia de datos que reflejarían un ambiente sagrado (Carriazo 1973: 292-293). No obstante, la idea de que en el Carambolo se ubicara un centro de culto más que un simple hábitat permaneció mucho tiempo en estado embrionario. A pesar de las observaciones de Carriazo, la idea de que allí existió un templo fue adelantada en realidad de forma explícita por A. Blanco Freijeiro (1979: 95-96), quien imaginó un santuario tartésico ubicado en un asentamiento también tartésico. Pese a reconocer las fuertes influencias orientales, especialmente en el tesoro que dio fama al yacimiento, no reparó en que el exvoto de Astarté del Museo Arqueológico Hispalense, cuya procedencia del Caram- bolo él mismo aclaró (Blanco 1968: nota 5), sugería vínculos fenicios. Contaba con tanta fuerza el axioma «fenicios en la costa/tartesios en el interior», que todo lo oriental procedente de las tierras andaluzas no litorales se creía reflejo de la orientalización de los indígenas, sin que casi nadie sostuviera la implantación directa de colonos semitas. Hacía muchos años que la propuesta de G. Bonsor (1899) sobre la presencia de población oriental asentada en la comarca de los Alcores estaba relativamente aparcada.

En contra de la línea interpretativa que dominaba el panorama de la investigación, estudios más recientes han insistido en ver más un santuario con sus servicios anejos que un asentamiento con su templo correspondiente como había sugerido Blanco. En tal dirección, aunque sin pretenderlo, algunos trabajos prepararon el terreno a los últimos hallazgos, sobre todo al reivindicar el sentido religioso de ciertos ajuares cerámicos y de algunas estructuras excavadas por Carriazo (Belén y Escacena 2002: 169). Igualmente, otras aportaciones señalaban el carácter litúrgico de algunas piezas (Izquierdo y Escacena 1998) o experimentaban en explicaciones distintas sobre el papel del tesoro, que de ajuar de un monarca tartésico pasó a tenerse por atalaje para engalanar toros destinados al sacrificio y ajuar del sacerdote encargado del correspondiente rito (Amores y Escacena 2003).

Las excavaciones recientes en la parte superior del cabezo, en las que entraremos de forma más pormenorizada, han afianzado la interpretación del Carambolo como recinto de culto (Fernández Flores y Rodríguez Azogue 2005). Según estas intervenciones, el edificio comenzó como una humilde estructura rectangular con eje longitudinal este-oeste subdividida en tres espacios: un patio y dos estancias cubiertas al fondo de éste. Luego, esta primera construcción conoció varias remodelaciones que agrandaron el conjunto y lo dotaron de más lujo, hasta el punto de constituir hoy el mayor recinto religioso conocido del Hierro Antiguo hispano.

El exvoto de Astarté procedente del Carambolo, y hallado antes de la aparición del tesoro en 1958, sugiere la dedicación del santuario a dicha divinidad fenicia, lo cual no contradice la celebración en él de cultos a 


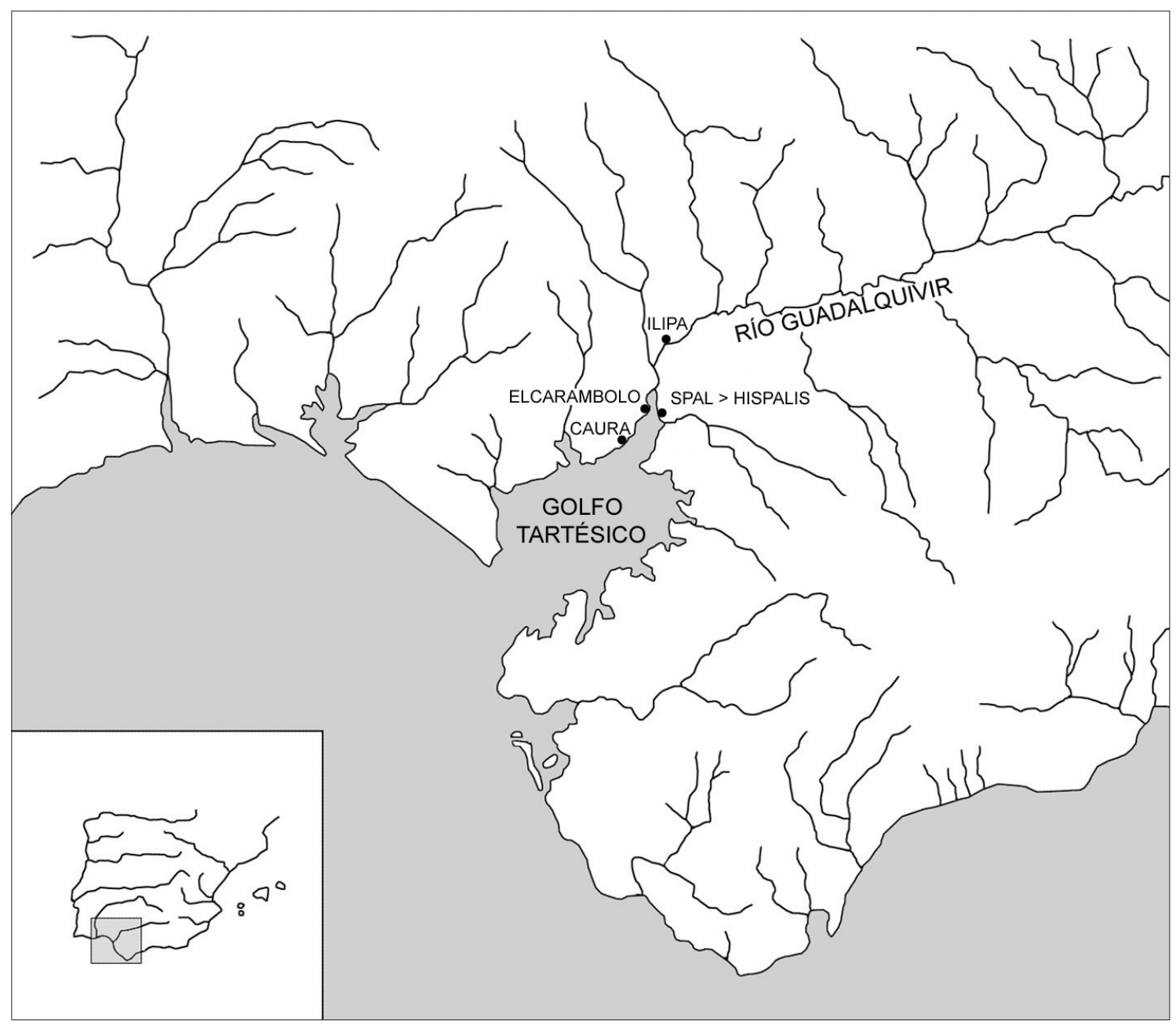

Figura 1. Situación del Carambolo en el contexto del paleoestuario del Guadalquivir.

Baal/Melqart. De ahí se deduciría su carácter semita, una vinculación étnica y cultural acrecentada por otros hallazgos aún inéditos en parte, entre ellos diversos fragmentos de huevos de avestruz y algunos escarabeos, además de la embarcación objeto del presente artículo.

El Carambolo, situado al oeste de Spal (Sevilla) en uno de los cerros más altos de la cornisa oriental del Aljarafe, ocupaba una elevación singular de la orilla derecha del paleoestuario del Guadalquivir, muy cerca -apenas $10 \mathrm{Km}$ - de su antigua desembocadura en Caura (fig. 1). Si es éste el paisaje descrito por la Ora Mariti$m a$ en las bocas del gran río de Tartessos, y si es correcta la identificación de Caura con el Mons Cassius (Belén 1993: 49), este sitio puede corresponder al que Avieno (259-261) llama Fani Prominens. Por lo común, tal topónimo se ha traducido como "cabo sagrado" o "cabo del templo" (cf. Schulten 1955: 159), en la idea de que la voz prominens se refiere a una prolongación horizontal de la costa. Pero las reconstrucciones paleogeográficas aconsejan asignarle la acepción vertical de su significado, acorde con lo que fue el Carambolo en su entorno inmediato durante su época de vida entre el siglo IX y el primer cuarto del VI a.C.: el "promontorio del santuario".

\section{EL CARAMBOLO. UN NUEVO PANORAMA TRAS LOS RECIENTES TRABAJOS DE CAMPO}

El hecho de que J. Maluquer de Motes colaborara en los trabajos del Carambolo Alto (Aubet 1992-93), llevados a cabo por J. de M. Carriazo al poco de encontrase el tesoro en 1958, influyó en que el yacimiento se interpretara como "fondo de cabaña". Sin embargo, Carriazo 
(1970: 58-59; 1973: 233-234) expresó sus dudas sobre tal explicación, por lo que apuntó también la hipótesis que veía en dicha estructura los restos de una posible pira funeraria. Cuarenta años después de aquella primera intervención arqueológica, la información lograda entonces ha sido estudiada bajo un enfoque teórico y metodológico distinto, y especialmente con hipótesis muy diferentes. Así, en el supuesto "fondo de cabaña" se ha visto una fosa ritual a la que se arrojaría el ajuar litúrgico ya inútil usado en los ritos de un santuario consagrado a Astarté (Belén y Escacena 1997: 114). Tan novedosa propuesta careció en principio de una acogida favorable entre los especialistas, de manera que fue refutada a favor de nuevo del uso de la estructura como lugar de habitación (Torres 2002: 284). Es más, el nuevo papel atribuido a lo descubierto por Carriazo en el Carambolo Alto ni siquiera ha sido contemplado por análisis posteriores a las recientes excavaciones en el cabezo, como es, por ejemplo, el de A. Delgado (2005). No obstante, estos últimos trabajos de campo realizados entre 2002 y 2005 han demostrado que el hipotético "fondo de cabaña" no constituyó en su día más que una fosa irregular a la que fueron a parar los más lujosos elementos amortizados en el uso de un enorme edificio -en su máximo desarrollo contó con casi $4.500 \mathrm{~m}^{2}$ - cuya función fue evidentemente la de santuario (Fernández Flores y Rodríguez Azogue 2005; Rodríguez Azogue y Fernández Flores 2005).

La construcción conocida ahora en el Carambolo Alto comenzó con un recinto mucho más pequeño, que, con sólo tres estancias, presentaba en conjunto una estructura rectangular orientada según el eje marcado por el orto solsticial de verano y el ocaso solsticial de invierno, con entrada por el este. Antes, el terreno fue nivelado y posiblemente purificado mediante la quema ritual de la superficie que iba a ocupar el recinto sagrado. Tal preámbulo ocasionó unos filamentos de carboncillos que han suministrado una fecha radiocarbónica calibrada del siglo IX AC, casi cien años anterior a la que se tenía tradicionalmente como comienzo de la colonización fenicia en el Guadalquivir inferior. Entre la muy escasa documentación de ese nivel quemado se constata ya cerámica a torno, y a esa misma época tan vieja de la presencia semita podrían corresponder dos pequeñas ánforas del Carambolo Bajo, publicadas ya en su día por Carriazo (1973: fig. 419), cuyos perfiles recuerdan la vieja tradición cananea heredada del segundo milenio a.C. Por tanto, el establecimiento de los fenicios en la zona de Sevilla puede situarse ya en los mismos momentos que en Huelva y que en las más viejas colonias de la costa andaluza mediterránea; y, aunque la fosa ritual del Carambolo que se interpretó como fondo de cabaña no corresponde a la época del templo inicial (V), sino a una fase algo más tardía (Santuario III, de la primera mitad del siglo VIII a.C.), en ella se ha hallado un fragmento de cerámica sarda de la misma clase, aunque con distinta decoración, que el recientemente valorado por M. Torres (2004). En cualquier caso, el hallazgo en su día, sobre el relleno de esta estructura, del tesoro que ha dado fama al yacimiento demuestra que los últimos objetos depositados en dicho sitio corresponden al episodio de violencia que acabó con el último edificio (Santuario I). Por otra parte, los trabajos recientes han descubierto, junto a esta estructura que contenía el supuesto fondo de cabaña, otras fosas situadas también dentro del recinto sagrado y que tendrían la misma función: ser el destino de los ajuares litúrgicos amortizados en el culto. En una de las recientemente estudiadas, la que contenía el barco objeto del presente artículo, se ha documentado un fragmento de cerámica griega que pudo pertenecer a un escifo del Geométrico Medio II Ático, fechado en cronología arqueológica tradicional en la primera mitad del siglo VIII a.C.

En relación con los principales problemas historiográficos planteados en el apartado anterior, los últimos trabajos de campo en el Carambolo han demostrado básicamente dos cosas: que su cronología no es precolonial -lo que hay anterior corresponde a sendas y pequeñas ocupaciones del Calcolítico y del Bronce Pleno- y que desde sus comienzos fue un santuario oriental, no un poblado indígena de cabañas. En la primera mitad del siglo VI a.C., cuando la demanda de la plata tartésica desde Oriente queda cortada por la conquista babilónica de las metrópolis fenicias de la costa libanesa, acaba el santuario del Carambolo. Entre el siglo IX a.C. y esta fecha final, el edificio conoció cinco construcciones superpuestas ${ }^{1}$. De todas esas fases, la relacionable con nuestro barco corresponde con toda probabilidad al edificio IV, que contaba con un espectacular altar en forma de piel de toro muy parecido a la silueta de los «pectorales» del tesoro ${ }^{2}$.

\section{EL HÍPPOS DEL CARAMBOLO IV}

La embarcación de cerámica hallada en el Carambolo se conserva aproximadamente en un tercio de lo que debió de constituir la pieza completa (fig. 2). Aunque lo que de ella podemos afirmar puede deducirse directamente sólo de esta parte que ha pervivido, algunas hipó-

\footnotetext{
1 Por si futuros trabajos pudiesen constatar recintos sagrados más viejos, tales expedientes arquitectónicos se han numerado desde arriba (templo más moderno) hasta abajo (templo más antiguo) con sistema romano: Santuarios I, II, III, IV y V.

2 Entrecomillamos el término «pectorales» porque una hipótesis reciente los ha reinterpretado como frontiles que adornarían la testuz de bóvidos destinados al sacrificio (cf. Amores y Escacena 2003: 20).
} 


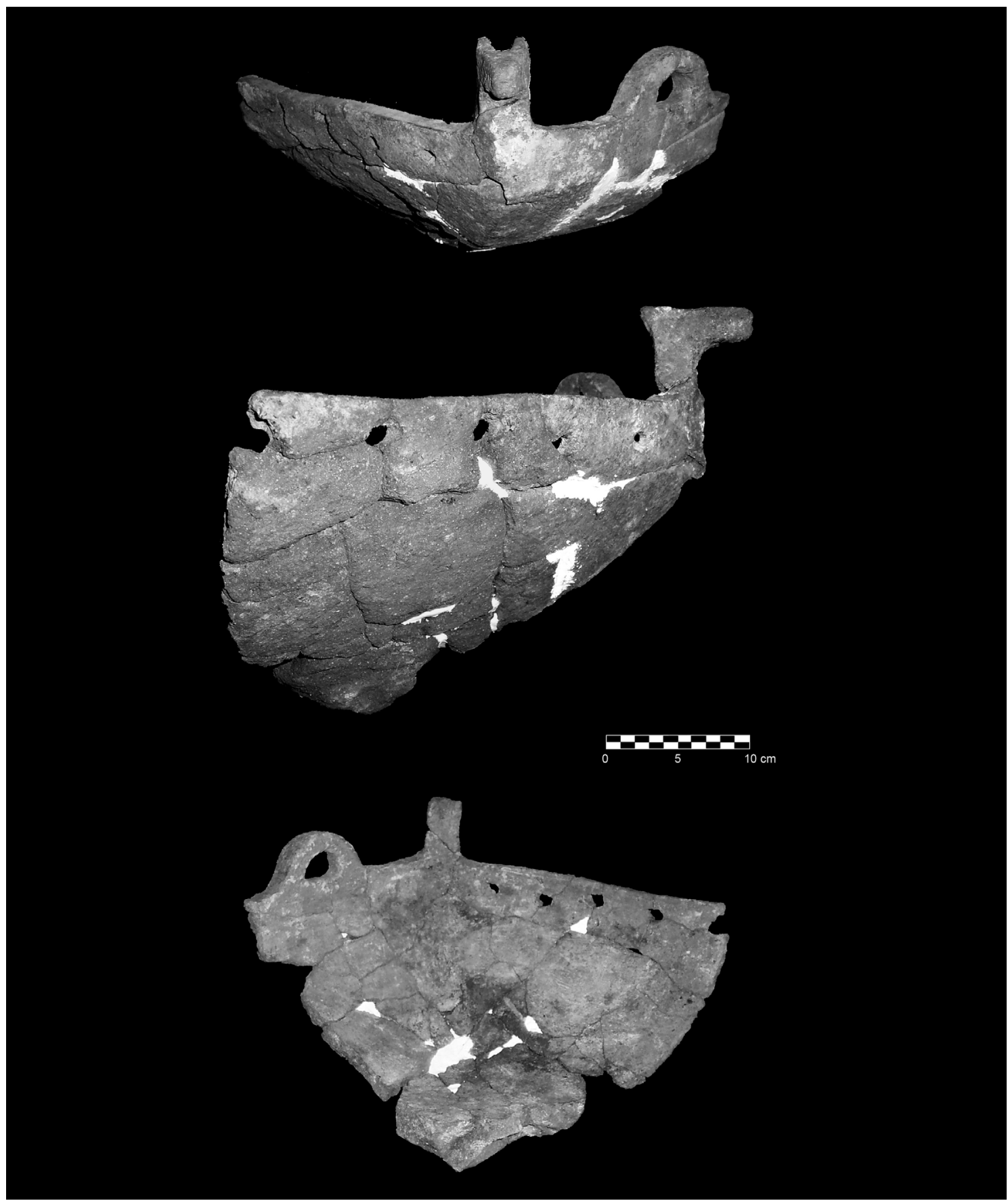

Figura 2. Híppos del Carambolo. Vistas frontal exterior (arriba), lateral (centro) e interior (abajo).

tesis sobre el modelo de nave al que este ejemplar representa pueden obtenerse de una reconstrucción imaginaria, por simetría delanteroposterior, a partir del trozo que nos ha llegado, así como de las representaciones de barcos fenicios en el arte del Próximo Oriente antiguo.
La parte conservada de nuestra nave cuenta con 30 $\mathrm{cm}$ de longitud por $35 \mathrm{~cm}$ de anchura (figs. 3 y 4). Con tales medidas, y teniendo presente que todo apunta a que lo hallado corresponde a poco menos de un tercio del objeto original -posiblemente la amura- la embarca- 


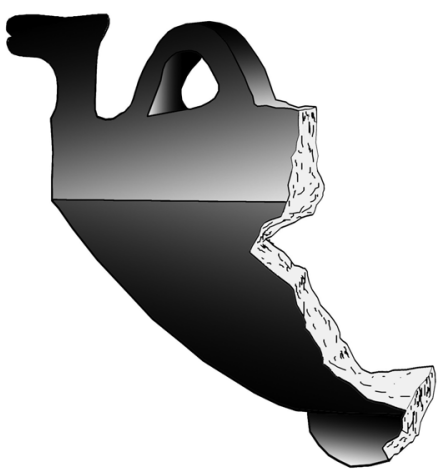

A

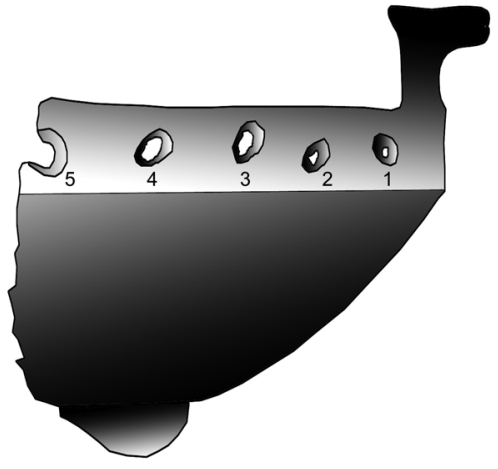

$10 \mathrm{~cm}$

Figura 3. Barco del Carambolo. A) Vista exterior desde el lado del asa. B) Vista exterior desde el lado de las gateras. Para hacer más comprensible la forma de la embarcación, en esta figura y en la siguiente se han eludido las múltiples líneas de fractura que presenta la pieza.

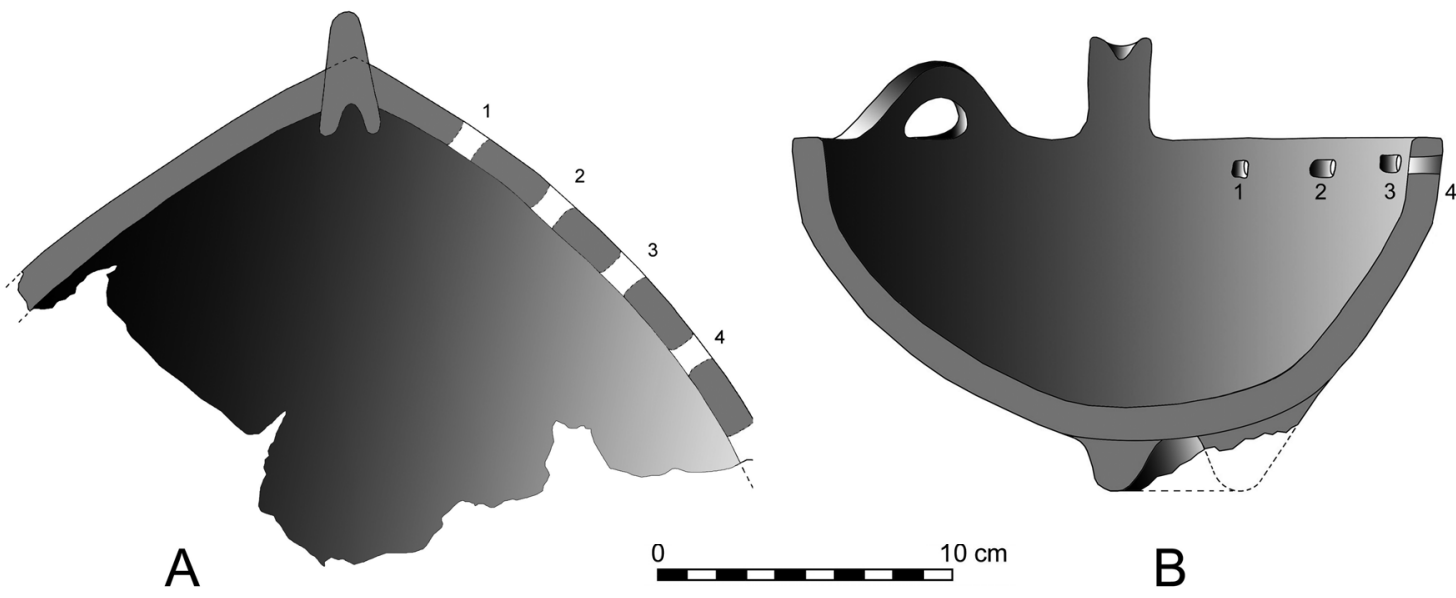

Figura 4. Vistas interiores del híppos sagrado del Carambolo. A) Perspectiva vertical. B) Perspectiva horizontal (sección a la altura de la gatera $n^{\circ} 4$ ).

ción completa pudo tener quizás algo más de $1 \mathrm{~m}$ de eslora y alrededor de $40 \mathrm{~cm}$ de manga ${ }^{3}$. Muestra un arrufo, o línea curva de la quilla, bien definido, si bien en la parte inferior del barco éste se convierte en un pie macizo de cerámica de forma más o menos anular sobre el que reposaría la nave, expuesta en algún lugar visible del santuario. Casi toda la pieza despliega la curvatura normal que tendría el cuerpo del barco real al que imitaba, lo que se observa más que nada en la parte correspondiente a la obra viva. En cambio, la obra muerta

3 Los términos técnicos sobre arquitectura naval empleados en el presente trabajo corresponden al glosario incluido en Guerrero (1993). cuenta con una carena nítida a partir de la cual se eleva en vertical la borda. Entre esa línea de carenación y la parte superior de la regala se perforaron las gateras, es decir, los orificios de salida de los remos. A pesar de que la mayor parte de las emulaciones de barcos que cuentan con tales agujeros los muestran en los dos flancos, en el caso del ejemplar del Carambolo se realizaron sólo en uno, ya que posiblemente la pieza estuvo arrimada a alguna pared y sólo podían verse los remos de una borda. Si estuviéramos ante la proa -lo que no es seguro como veremos-, las gateras conservadas, en número de cuatro completas y el inicio de una quinta, corresponderían a la banda de estribor. Desde su fabricación, la maqueta contó al menos con un asa vertical sobre una de las bordas para colgarla o atarla a algún elemento que le 


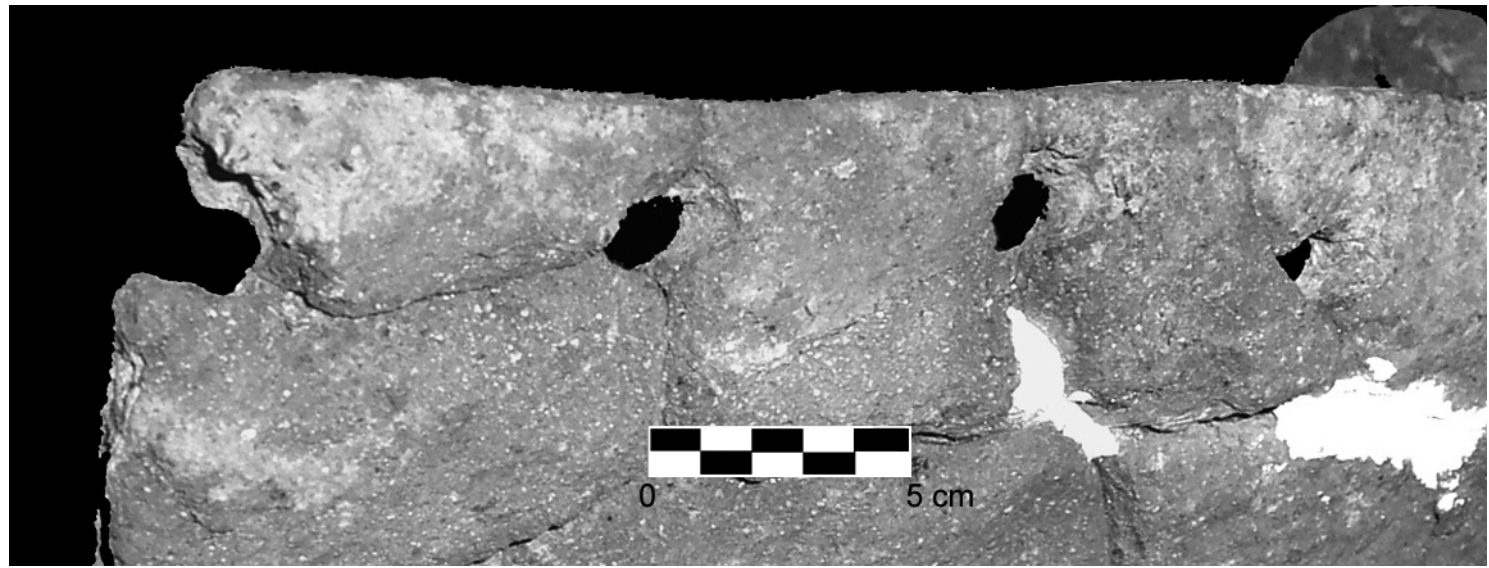

Figura 5. Perspectiva de las gateras desde el exterior de la embarcación.

proporcionara seguridad. La presencia de asas en réplicas de barcos es una característica observada en ejemplares votivos chipriotas, si bien en estos paralelos se explican casi siempre por tratarse de vasijas cerradas en forma de nave (cf. Karageorghis 2004: fig. 5.1). Ya que la pieza del Carambolo cuenta con una base anular, parece razonable pensar que, más que colgada, estuvo expuesta sobre un banco o poyete adosado a un muro. Tal destino pudo ser conocido por el artesano que la diseñó, de ahí que no cuente con asas repartidas de forma simétrica y que las gateras para los remos sólo aparezcan en el lado contrario al del asa, es decir, en el flanco que miraba al observador.

A partir de esta descripción mínima puede llevarse a cabo un intento de identificar la embarcación real a la que esta maqueta intentó imitar. Para ello, quizás las imágenes más útiles -por elocuentes- que nos han llegado sobre naves fenicias sean sobre todo las que aparecen en los relieves asirios de la primera mitad del primer milenio a.C., testimonios en principio sincrónicos de la pieza del Carambolo. Algunas veces, tales representaciones muestran embarcaciones no del todo simétricas, en el sentido de que, vistas de perfil, exhiben una proa ligeramente distinta de la popa. Pero otras veces la simetría es completa, luciendo los mismos elementos sobre la roda que sobre el codaste, algo que aquí nos importa especialmente para identificar en lo posible la nave representada. Tales particularidades ofrecen ya algunas claves para poder interpretar con mayores garantías de verosimilitud el barco del Carambolo, aunque no facilitan del todo la cuestión.

Conocemos viejas naves cananeas a través de algunas pinturas egipcias en las que se plasmó al parecer el tipo de carguero más pesado, el gaulós, término griego para designar a los mercantes fenicios más comunes que deriva de la raíz fenicia $* G W L$ (Bartoloni 1995: 286). Se trata sobre todo de las escenas que adornan las tumbas de
Kenamon y de Nebanun, además de las de la sepultura 162 de Tebas (Guerrero 1998: 64). Pero constituyen documentos más cercanos a los momentos que ahora nos interesan los compilados por M.E. Aubet (1994: 42-44) con motivo del análisis de la expansión colonial fenicia hacia Occidente. Uno recoge una representación de las puertas del palacio de Salmanasar III en Balawat, fechadas en el siglo IX a.C. En esta narración unas embarcaciones se aproximan por el Mediterráneo a la ciudad de Tiro, que aparece amurallada a la izquierda de las naves sobre un islote. Un conjunto más numeroso de mercantes quedó registrado en un bajorrelieve del palacio de Sargón II en Khorsabad que se data en el siglo VIII a.C., hoy en el Museo del Louvre. Aquí, las embarcaciones también se aproximan a dos ciudades situadas en la costa: Arvad, frente a Chipre, y Tiro, más al sur. La tercera estampa recogida por Aubet se ubicó en su día en la residencia ninivita de Senaquerib, y cuenta en imágenes bastante detalladas el episodio de la salida desde Tiro hacia las colonias -se ha supuesto que hacia Kition- del rey Luli de Sidón, que tuvo que huir en 701 a.C. como consecuencia de la toma por parte de los ejércitos asirios de las ciudades cananeas de la costa ${ }^{4}$. Este último bajorrelieve se fecha hacia 690 a.C., y la importancia que adquiere ahora tiene que ver, sobre todo, con la plasmación detallada de las filas de remos de las que van dotadas las embarcaciones, porque tales elementos, que no se

\footnotetext{
4 La tradición historiográfica española no suele llamar cananeos a los fenicios del primer milenio a.C., ya que reserva este etnónimo para las poblaciones siropalestinas del milenio anterior. Sin embargo, ambos gentilicios pueden usarse como sinónimos, lo que aquí hacemos porque los fenicios se denominaban a sí mismos can'ani (Aubet 1994: 17). La voz Canaán aplicada a su país de procedencia estaba vigente en Palestina aún en los siglos V y IV a.C., en especial al referirse concretamente a Fenicia (Liverani 2004: 327).
} 
detallan en los demás paneles, salen de las amuras a través de sendos orificios (cf. Stager 2004: 182). En cualquier caso, este último testimonio tiene menor importancia para usarlo en el estudio del barco del Carambolo, ya que en nuestro caso sólo aparece una fila de agujeros de salida de los remos mientras que los buques del destierro de Luli son birremes, como corresponde a barcos que por ello deben pertenecer a una armada según ha puntualizado V.M. Guerrero (1998: 66).

Como ya hemos adelantado, en el barco de cerámica del Carambolo aparecen efectivamente esas perforaciones (fig. 5), pero no las grandes gateras necesarias para los timones, que irían a popa como muestra una pintura cartaginesa del puerto de Útica (Guerrero 1998: fig. 9). Esto indica que nos encontramos tal vez ante la proa, lo que no deja de ser sólo una hipótesis de trabajo. En cualquier caso, y dada su extraordinaria versatilidad, las naves de carga a las que esta reproducción en cerámica aluden se desplazaban en alta mar a vela, sirviendo los remos sólo para maniobrar en puerto o en otros momentos en que obligaran las circunstancias (Díes Cusí 2004: 61). El desplazamiento mediante la fuerza humana era indispensable, por ejemplo, en la navegación por los estuarios, arterias del comercio fenicio (Barthélemy 2000), ya que la abundancia de meandros exigía cambiar la orientación de marcha sin que mudaran los vientos.

Nuestro barco conserva al menos un prótomo en forma de cabeza de caballo (fig. 6), lo que podría servir para identificarlo con el tipo de nave fenicia conocida con el nombre griego de híppos. Pero, como en la Unidad Estratigráfica 1025 apareció otra cabeza de caballo similar, no está claro si se trata de dos barcos distintos o de uno solo que representaba una nave con prótomo de cabeza de caballo tanto sobre la roda como sobre el codaste, es decir, en la popa y en la proa.

A favor de la primera conjetura-que las dos cabezas de équidos correspondan a sendas piezas que sólo las llevarían bien en la proa bien en la popa- puede traerse a colación el bajorrelieve ya citado del palacio de Sargón II en Khorsabad. Si en dicha escena los remeros están representados correctamente, mirando hacia la parte trasera del barco para poder desempeñar mejor su labor, la cabeza de caballo correspondería a un mascarón de popa ${ }^{5}$, pues estos tripulantes dan la cara a dicha parte, mientras que ofrecen la espalda a lo que por tanto sería la proa, que va adornada con un emblema en forma de abanico que recuerda la cola de un pez (Bartoloni

5 J. M. Luzón (1988) utiliza para nombrar estos elementos de adorno del barco dos términos griegos: akrostólion y akrotérion. Sin embargo, algunas traducciones dan por acrostolio el espolón de una nave, mientras V. M. Guerrero (1998: 86) lo asimila simplemente a la roda. Al ser la que más acuerdo suscita por su etimología, aquí usaremos sólo la voz akrotérion para referirnos al mascarón de proa que imita una cabeza de animal.

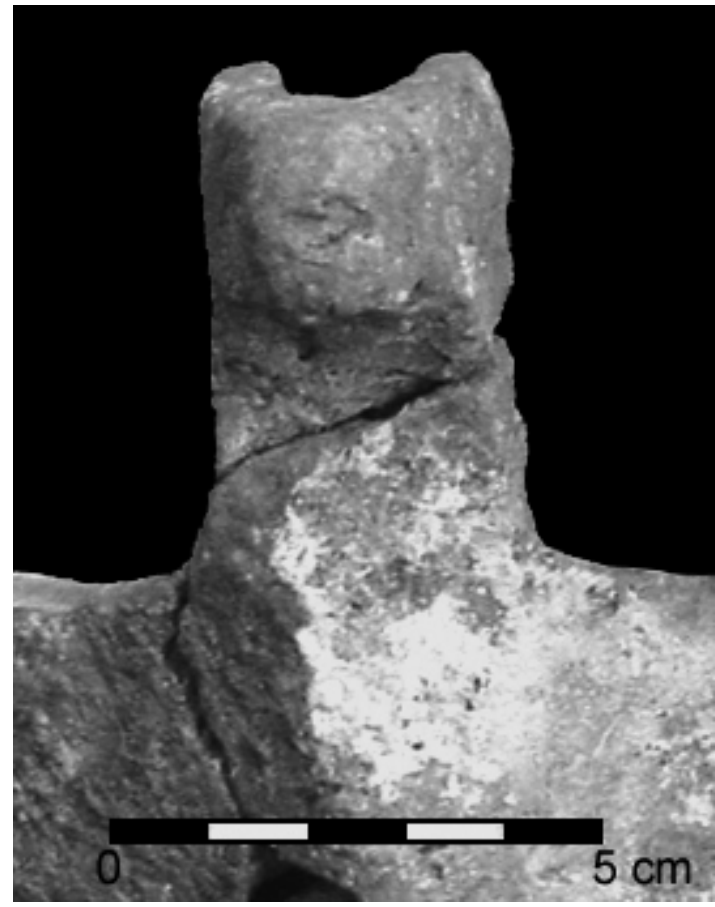

Figura 6. Detalle de la cabeza de caballo que identifica la nave como híppos fenicio.

1988a: 74). A pesar de lo cual, el hecho de que tales embarcaciones remolquen tras ellas maderos flotantes parece hablar de todo lo contrario, es decir, de que el prótomo de caballo corresponde a la proa, y que tal vez los remeros se representaron excepcionalmente mirando hacia la parte delantera de las naves porque no estaban haciendo su trabajo en alta mar, sino que realizaban una maniobra de aproximación a puerto para la que habrían invertido su posición normal de trabajo ${ }^{6}$.

No obstante, la iconografía que adorna las puertas de Balawat muestra embarcaciones en las que las cabezas del animal coronan tanto la proa como la popa, disponiendo en ese caso cada embarcación de dos mascarones (Mazza 1988: 559). A favor de esta segunda posibilidad habla el hecho de que, en apariencia, en las dos cabezas de caballo localizadas en el Carambolo no se observan diferencias sustanciales en la composición de

6 J. Alvar resuelve de otra forma esta posición de la tripulación un poco problemática: que en vez de auténticos remos se estén empleando canaletes (Alvar 1981: 52). Dicha hipótesis exigiría una obra muerta de muy escasa altura sobre el agua, hasta el punto de que estos híppoi serían casi canoas, lo que choca con la pesada carga que transportan aunque ese tipo de embarcación abunda desde tiempos prehistóricos (cf. Greenhill 1976: 124-135) y eran relativamente usuales en el mundo antiguo del Mediterráneo oriental (De Graeve 1981: 107-109). 


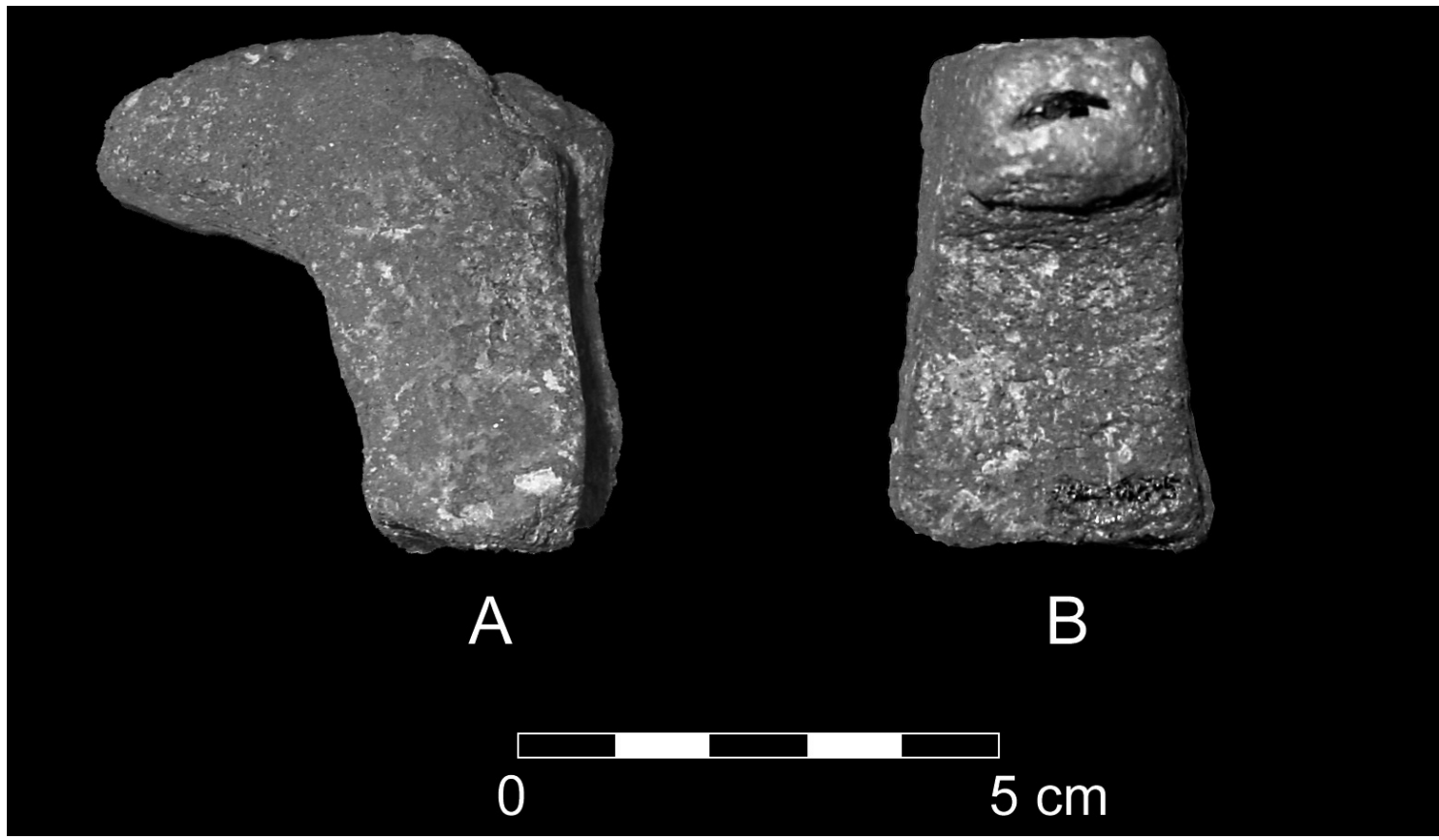

Figura 7. Otra cabeza de caballo procedente de la UE 1025. Está elaborada en el mismo tipo de arcilla que el resto del barco; igualmente, presenta como aquél, restos de engobe rojo. En consecuencia, puede corresponder al otro extremo de la misma embarcación.

la pasta cerámica; tampoco en su tratamiento, coloración y grado de cocción (fig. 7). En consecuencia, pueden corresponder tanto a un mismo objeto como a dos piezas distintas realizadas por un único taller. De confirmarse con futuros análisis de la pasta cerámica que se trata de una sola nave, como sospechamos, el ejemplar del Carambolo estaría copiando fielmente el tipo de embarcación fenicia que muestra una simetría delanteroposterior bastante alta, observada en los casos reales de los pecios 1 y 2 de Mazarrón (Negueruela y otros 2000: fig. 2; Negueruela 2004: 240), aunque estos últimos carecen de cualquier tipo de akrotérion. Igualmente, sería similar a la pequeña nave que decora un sello del tesoro de la Aliseda del siglo VII a.C. (Almagro-Gorbea 1977: 209 y lám. XXX), con un ambiente nilótico en el que dos personajes aparecen sobre una barca con sendos prótomos a proa y popa en los que V.M. Guerrero (1993: 124) ve con razón cabezas de aves más que de caballos ${ }^{7}$. Este tipo de nave simétrica

\footnotetext{
7 El contexto nilótico se aprecia, por ejemplo, en la presencia de flores de loto en la escena. En cualquier caso, que se trata más bien de una barcaza de río se puede deducir bien de la presencia de un único remero situado en la parte trasera de la embarcación, como otros muchos ejemplos similares del mundo oriental (cf. Arkell 1959: fig. 3).
}

parece ser la representada en las puertas del palacio de Salmanasar III en Balawat, y su existencia real ha sido confirmada no hace mucho en los pecios de la costa española de Mazarrón (Alicante), fechados en la segunda mitad del siglo VII a.C. tanto por los elementos cerámicos de la carga que trasportaban como por análisis radiocarbónicos (Negueruela 2004: 237-238) ${ }^{8}$. De tratarse de este modelo, estaríamos ante embarcaciones de doble quilla (en proa y popa) y de timón con dos aletas (a babor y a estribor), elementos cuya invención se atribuye tradicionalmente a la marina fenicia y que facilitaron la maniobrabilidad de las viejas naves

\footnotetext{
8 Los barcos de Mazarrón carecen de akrotérion. Aunque se tienen normalmente por fenicios, esto se ha deducido en realidad de su flete. Sin embargo, algún detalle constructivo ausente en la tradición náutica de la marina semita oriental, o que se da por tal, ha hecho pensar en la posibilidad de que se trate de embarcaciones tartésicas que trasportaban una carga de productos fenicios (Guerrero 2004: 116, nota 36). En contra de esta sospecha de V.M. Guerrero hablaría el hecho de que parte de la madera usada en su construcción es cedro (Negueruela 2004: 237), una especie citada precisamente para la carpintería naval de los astilleros de Tiro por Ezequiel (XXVII, 5) y que pertenece a un género, el de las coníferas, muy usado en la carpintería naval antigua debido a su elasticidad (Guibal y Pomey 2003: 36).
} 
panzudas y de los mercantes de tipo egeo heredados por los cananeos desde la Edad del Bronce al menos (Aubet 1994: 155) ${ }^{9}$.

En las representaciones orientales, los barcos fenicios de guerra nunca llevan akrotérion en forma de cabeza de caballo. Por el contrario, presentan la popa con perfil arqueado y un espolón muy desarrollado en la proa. Este elemento de combate en posición frontal, auténtico ariete en los enfrentamientos navales, suponía un potente armamento cuya primera adopción se atribuye también a los fenicios, en este caso en el siglo VIII a.C. Como sugiere el bajorrelieve del palacio de Senaquerib en Nínive, tal elemento se aplicó en principio a embarcaciones de dos filas de remeros (birremes), aunque fue luego usado a lo largo de un milenio por las flotas del Mediterráneo antiguo en distintos modelos de navíos bélicos. Todas estas características de la flota de guerra excluyen que el barco del Carambolo represente otra cosa que una nave de transporte de mercancías, lo que está acorde con uno de los objetivos de la colonización fenicia de Occidente: el comercio ${ }^{10}$.

Para el trasporte naval, los fenicios usaron al parecer dos tipos de embarcaciones: el híppos (caballo) y el gaulós -en terminología griega- o gôlah fenicio (bañera) ${ }^{11}$. Por el significado de la voz griega con que el nombre del primero nos ha llegado, se ha creído tradicionalmente que el gaulós excluiría la posibilidad de contar con un prótomo de caballo en proa y/o popa. No obstante, tiene razón M.E. Aubet (1994: 155-156) al señalar que esos mascarones teriomorfos adornaron en su momento tanto pequeñas embarcaciones de pocos remeros como otras de mayor eslora y con una tripulación más numerosa. De hecho, si en las puertas de Balawat se representa una ligera barcaza de carga conducida sólo por dos tripulantes, el relieve del palacio de Sargón II en Khorsabad muestra en cambio una flota en la que los barcos con prótomo de caballo se desplazan con la fuerza de cuatro o cinco remeros. Sin embargo, cuando se comparan entre sí los tamaños de los objetos representados en dichas escenas, parece razonable deducir que, como el artista no intentó plas-

9 En contra del doble timón en los híppoi se ha pronunciado V. M. Guerrero (1998: 78).

${ }^{10}$ Hoy, cuando los inicios de la colonización fenicia en la Península Ibérica se fechan en el siglo IX a.C., no parece adecuado negar, por lo menos desde finales del siglo VIII y en coincidencia con un auge de la presión asiria sobre las metrópolis orientales, otros intereses además de las comerciales. No obstante, parece que fueron éstos los que abrieron brecha en calidad de "finalidades prioritarias" (Fernández Miranda 1988: 461).

${ }^{11}$ De la cymba, una tercera clase, se sabe tan poco que apenas aparece en la literatura arqueológica especializada. Podría tratarse de una variante del tipo gaulós (Alvar 1981: 54). mar más que una idea genérica o una propaganda política, no se respetaron las proporciones, y que por tanto la cantidad de remeros que en cada caso aparece no debe ser tomada como referencia exacta de la realidad. $\mathrm{Si}$ esas alusiones fuesen fotos directas de casos concretos, estaría claro que el número de agujeros para los remos que muestra el barco del Carambolo serviría para identificarlo más con las naves mercantes de Khorsabad que con las más pequeñas de Balawat; lo cual supondría asumir que la otra cabecita de caballo aparecida en el Carambolo pertenece a un barco distinto, porque la marina representada en el palacio de Sargón II está compuesta por navíos que llevan un único akrotérion.

Precisamente en esta escena del bajorrelieve de Khorsabad aparecen barcos tanto con mástil como sin él. Dado que en ambos casos sus tamaños son semejantes y el número de remeros también similar, podría pensarse que este elemento era abatible, como desmontables eran también otros aparejos (Guerrero 1998: 78), de manera que sólo se izaría sobre la carlinga en navegaciones de altura. Ya que el trozo conservado del barco del Carambolo no llega a la mitad de lo que pudo ser la embarcación completa, se nos ha perdido cualquier referencia aclaratoria de este problema, pero tal extremo está bien documentado en los pecios de Mazarrón (Negueruela 2004: 244 y fig. 24). La base donde encajar el palo vertical aparece igualmente representada en exvotos chipriotas de cerámica (Westerberg 1983: figs. $8,31,33$ y 48$)$.

Como la pieza del Carambolo se fabricó, en cualquier caso, más con la intención de realizar un objeto de culto que con la de hacer una versión exacta de la realidad, seguramente faltan y sobran detalles de otros elementos de los que debían disponer los buques fenicios de verdad. En este sentido, nos parece inapropiado deducir los posibles tamaños de los mascarones que iban sobre el codaste y/o la roda en función de las proporciones de esta copia en cerámica. Igualmente, ninguna medida transportable a la realidad se puede obtener sobre la manga y la eslora. Nuestro barco de cerámica carece además de cualquier detalle que determine el punto en el que se fijaba el estay que, dirigido hacia la proa desde la cofa, mantenía vertical el mástil y le proporcionaba solidez, si bien en una de las naves representadas con este detalle en el palacio de Sargón II en Khorsabad los sitios de sujeción del estay y de la burda serían respectivamente las prolongaciones verticales del codaste y de la roda, en nuestro caso representadas por los cuellos de los caballos que sirven de mascarones a la nave. Tampoco muestra el barco del Carambolo pormenor referido a dónde se ataban los obenques ni a cómo se sustentaban de babor a estribor los travesaños que servían de asiento a los remeros, que serían simples bancos al descubierto (Guerrero 1998: 77). Algunos de esos 


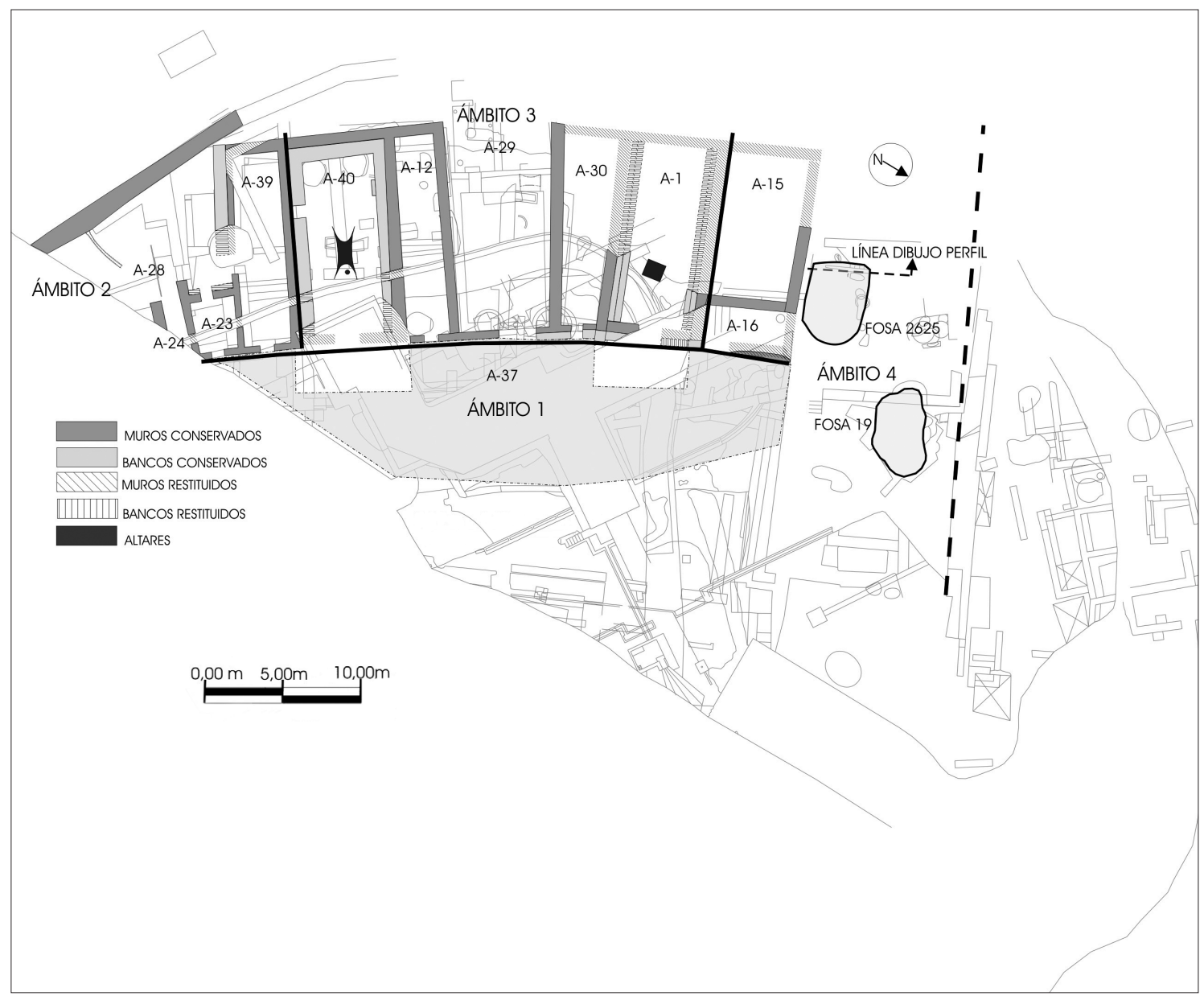

Figura 8. Lugar del hallazgo del barco (fosa UE 2625) en el contexto del Santuario IV del Carambolo.

rasgos los conocemos hoy gracias a los pecios de Mazarrón (Negueruela 2004: 241-244) ${ }^{12}$. En cambio, y como ya hemos señalado, no podían faltar algunos detalles que parecen responder sólo a la función litúrgica de este modelo: gateras en una sola banda, un pie anular para apoyar la pieza sobre algún expositor, y un asa que se prolonga verticalmente desde la borda y que sólo tendría la misión de atar el objeto para proporcionarle seguridad o de sostenerlo colgado en algún lugar del templo.

Cuando se compara lo mostrado por el barco del Carambolo con lo que se ha afirmado de los mercantes fenicios, las contradicciones parecen evidentes. Por eso, nuestra conclusión provisional es que el término híppos

\footnotetext{
${ }^{12}$ Aunque a veces se les llama baos a dichos tablones, otros especialistas definen los baos como "piezas transversales curvadas que unen las cuadernas de babor a estribor y sostienen la cubierta" (Guerrero 1998: 86).
}

transmitido por las fuentes escritas grecorromanas no se refiere tanto a un modelo concreto de embarcación cuanto a todas aquellas naves que disponían de un akrotérion en forma de cabeza de caballo, ya sobre la proa y la popa, ya sólo sobre la proa. De hecho, la consideración de que el híppos era necesariamente una nave más pequeña que el gaulós se ha deducido en parte de los bajorrelieves de las puertas de Balawat, cuando en esas mismas escenas aparecen también embarcaciones del mismo tamaño que carecen de cualquier tipo de akrotérion (cf. De Graeve 1981: fig. 42). En atención a la experiencia de Eudoxo en el puerto de Alejandría referida por Estrabón, en realidad el nombre híppos y el motivo al que aludía pudieron servir más como emblema étnico que como cualquier otra cosa. Tales símbolos de identificación de grupo fueron especialmente importantes durante el primer milenio a.C., cuando estaba candente el litigio por el control de las rutas del Mediterráneo central y occidental entre griegos y fenicios (Escacena 2006: 148). 


\section{EL SANTUARIO IV. CONTEXTO ARQUEOLÓGICO}

Los detalles referidos al ambiente arqueológico en el que apareció el barco del Carambolo añaden al estudio de la pieza un doble interés. Por una parte, suministran información sobre su cronología y sobre la posible funcionalidad de la fosa a la que sus restos se arrojaron. Por otra, proporcionan una visión general del contexto cultural y religioso del complejo en conjunto.

La primera construcción protohistórica sobre el Carambolo corresponde al Santuario V. Se trata de un pequeño edificio con orientación astronómica solar. La entrada se abre al este, dispuesta en concreto al orto del solsticio de verano, mientras la trasera da al oeste, hacia el ocaso del solsticio de invierno. Se trata de un templo sencillo compuesto de tres estancias: una de entrada, que parece patio, y dos al fondo cubiertas y más pequeñas, la meridional con un altar circular en su centro.

La primera ampliación de esta estructura más antigua corresponde al Santuario IV (fig. 8). La modificación consistió en levantar un edificio simétrico que tenía como centro y fondo el templo prístino, convertido ahora en patio. Así, surgieron al sur y al norte respectivamente de este nuevo patio dos habitaciones alargadas que contaron en su día con hogares y otras estructuras relacionadas con el funcionamiento cotidiano de un santuario: un horno, vasijas entibadas, hogares, molinos, etc. Abundan en este contexto los restos de fauna y las cenizas, señal de que se trataba de una zona tal vez destinada a la preparación de los sacrificios. A su vez, a ambos lados de estos compartimentos se construyeron sendas capillas: una en el flanco norte para Astarté y otra en el lado sur para Baal ${ }^{13}$. El centro de la capilla o tabernáculo meridional lo ocupó un gran altar en forma de piel de toro extendida sobre el suelo, fabricado mediante un suave rebaje del pavimento de tierra apisonada, luego pintado de rojo. La combustión de las ofrendas sobre este altar originó un gran círculo rubefactado

\footnotetext{
${ }^{13}$ Entiéndase el nombre Baal como apelativo genérico del dios masculino de los fenicios: el Señor. La manifestación concreta pudo ser en este caso Melqart. El uso indiscriminado de ambos términos referidos al mismo dios se apoya en la hipótesis de que los fenicios fueran en el fondo monoteístas por lo que se refiere al menos al ente masculino, pues tal divinidad va emparejada siempre con Astarté: Esmún-Astarté en Sidón, Baal Samem-Astarté en Biblos, Melqart-Astarté en Tiro y en la Cartago arcaica -luego, aquí, Baal Hammon-Tanit en época púnica-. De ser verosímil tal propuesta, bajo los apelativos Baal, Melqart o Adonis sólo se ocultarían distintas advocaciones. Algo afín ha manifestado G. del Olmo (2004: 28-29). Sobre tan polémico asunto, del que se ha dicho y escrito generalmente todo lo contrario de lo aquí propuesto, véase también Hornung (1999).
}

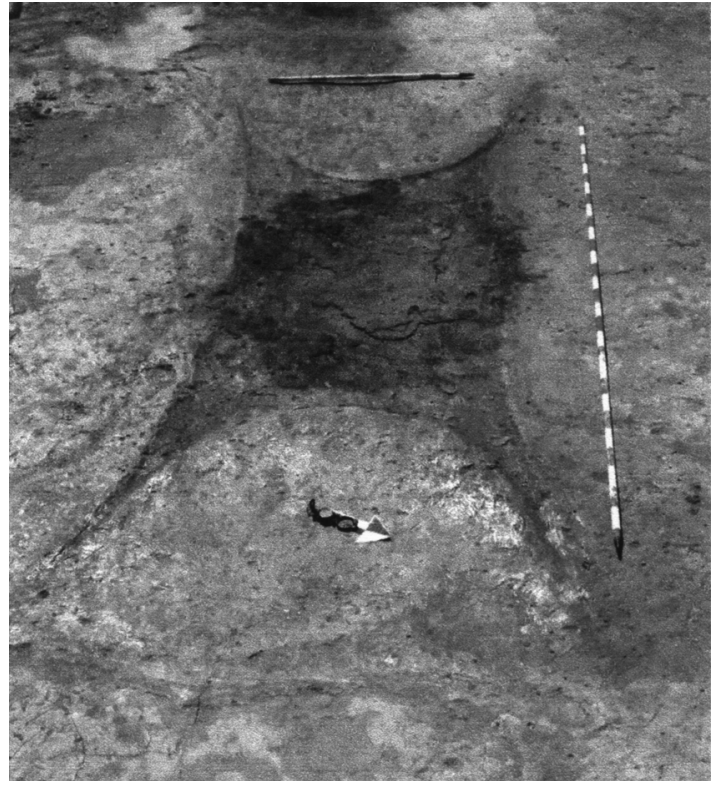

Figura 9. Altar en forma de piel de toro de la capilla meridional del santuario.

en el centro y ennegrecido en la periferia, que en algunas zonas sobresalía de los límites del ara (fig. 9).

Repintado y agrandado poco a poco, este mismo altar pervivió en la fase siguiente (Santuario III), en la que se añadió al complejo un gran espacio abierto de entrada pavimentado con guijarros de cuarcita, y por tanto apto para el acceso de mucho público y de caballerías en su caso. Entre este amplio sector a cielo abierto y las estancias del fondo (capillas de Astarté y Baal y otras áreas de servicio del templo), se dispuso un nártex pavimentado con conchas marinas del género Glycymeris, suelo tan delicado que necesariamente debió contar con un acceso más restringido que el ámbito precedente. En esta fase, el edificio conoció además una pequeña ampliación hacia el este de las habitaciones del fondo, especialmente de las capillas de Baal y Astarté.

Mientras estuvo en uso el edificio IV, en el flanco norte del complejo se abrieron una serie de fosas destinadas a acoger la basura sagrada originada en el ritual. En las distintas fases constructivas, las características de los materiales recuperados en tales vertidos son similares a las de los restos documentados en las áreas sacras destinadas a la preparación de las ofrendas y al culto, y completamente distintas de las que presentan los elementos exhumados en las edificaciones que se desarrollan al amparo del santuario pero fuera de él ${ }^{14}$.

${ }^{14}$ Este "barrio de servicios" se extiende por la ladera septentrional del cabezo del Carambolo. Su extremo inferior corresponde al "Carambolo Bajo" de Carriazo. 


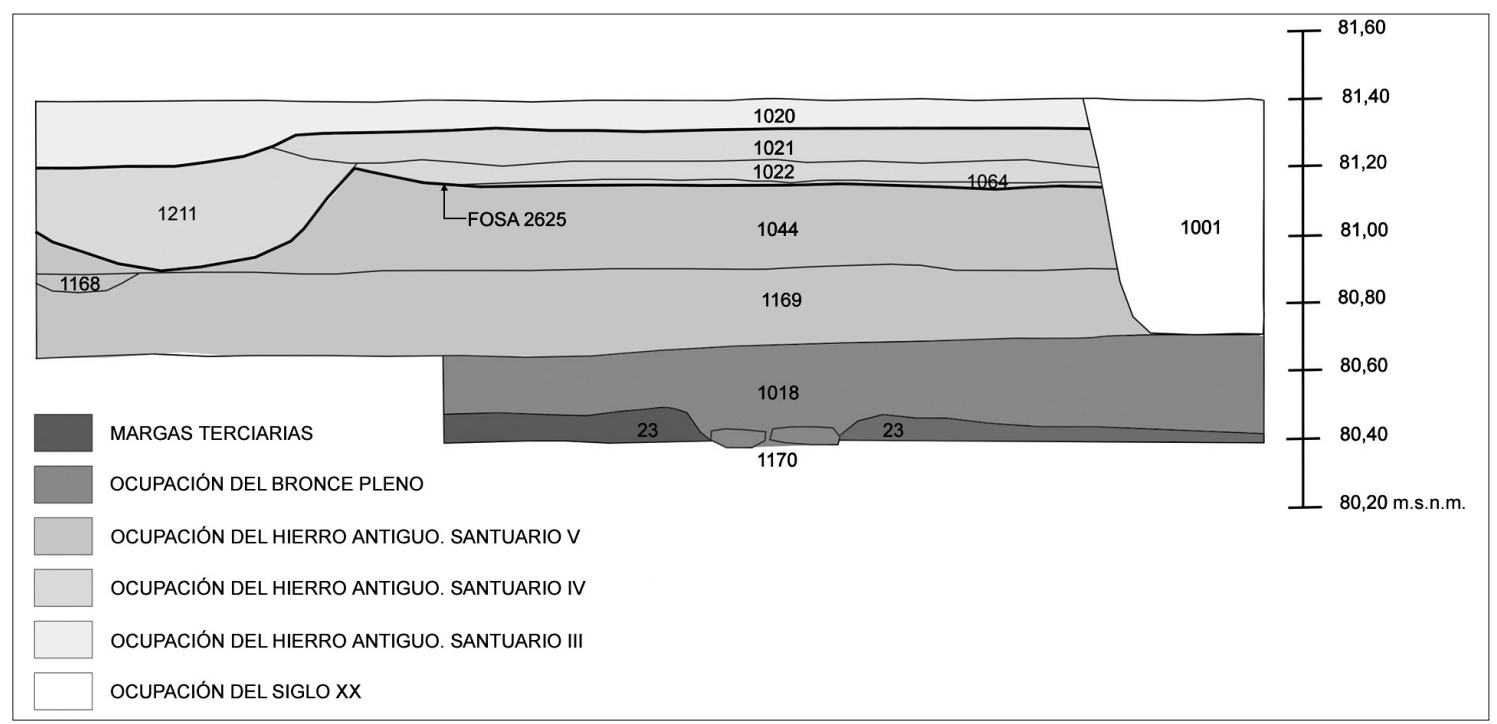

Figura 10. Sección estratigráfica del sector del hallazgo. La nave apareció amortizada en la UE 1022.

El navío apareció en una fosa de planta irregular y sección en segmento de círculo (UE 2625) colmatada por siete vertidos (UE 1021, 1022, 1024, 1025, 1027, 1064 y 1211). Tales rellenos se caracterizaban por su color negruzco o pardo-negruzco, su textura limosa y su baja compactación, con alguna arena, nodulillos de arcilla quemada, ripio cerámico y abundancia de ceniza y carbones (figs. 10 y 11). La tierra de estos depósitos casi igualaba en volumen a los restos arqueológicos que tales estratos contenían, destacando la alta proporción de huesos, malacofauna (especialmente Solen sp.) y elementos cerámicos. La Unidad Estratigráfica que cobijaba el barco (UE 1022) fue la que precisamente ofreció alguno de los elementos más singulares. De hecho, en ella se exhumaron una cadenilla de oro, con un trenzado similar al que muestra la que une los sellos al collar del tesoro del Carambolo, y varios pequeños apliques realizados en ese mismo material, junto a una notable cantidad de cerámica a torno y a mano. La UE 1022 presentaba características similares a las dos sobre las que se asentaba (UE 1064 y 1025), si bien se observaban ligeras diferencias en cuanto al color, grado de compactación y proporción de elementos, aspectos que dieron lugar a su diferenciación. En la UE 1064 apareció un borde de escifo del Geométrico Medio II Ático, que puede datarse hacia 780-760 a. C., mientras que en la UE 1025 se recuperó un prótomo de caballo similar al del barco objeto de estudio y que tal vez pertenecía a la misma pieza. De hecho, la diferencia entre las UE 1022 y 1025 se limitaba a una menor proporción de contenido y una coloración ligeramente distinta. En cualquier caso, el tiempo trascurrido entre la decantación de estos niveles debió de ser muy breve, ya que ninguno presen-

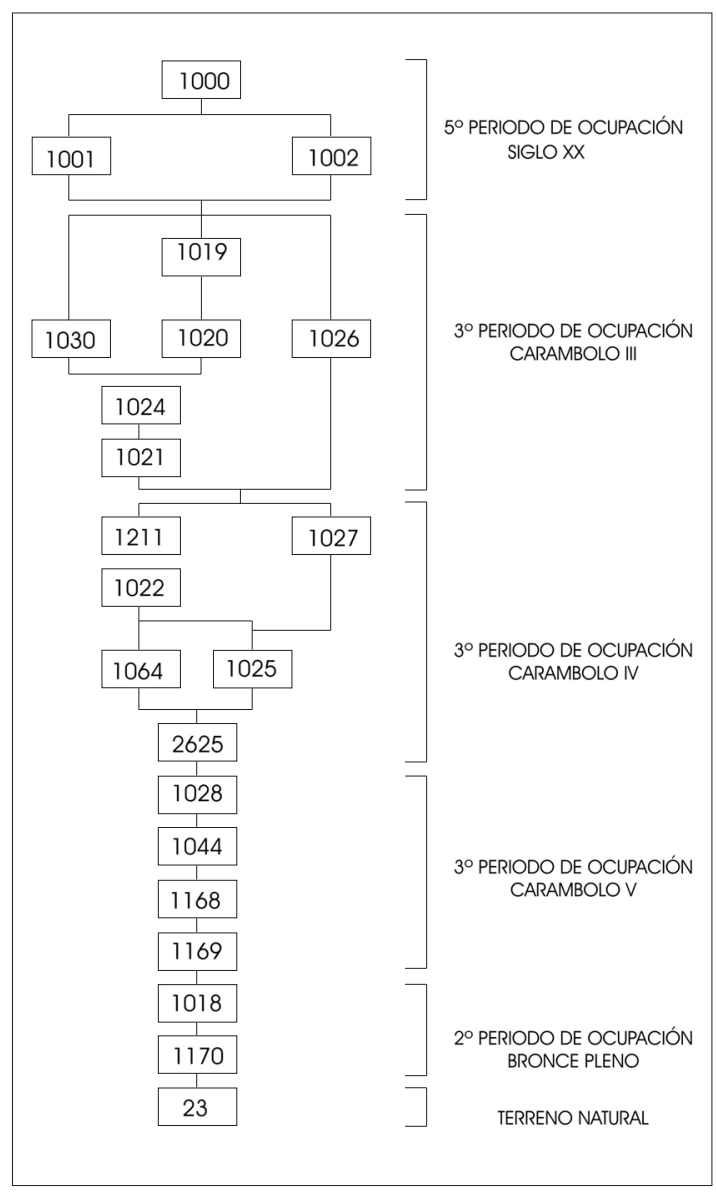

Figura 11. Relaciones estratigráficas de la UE 1022. 


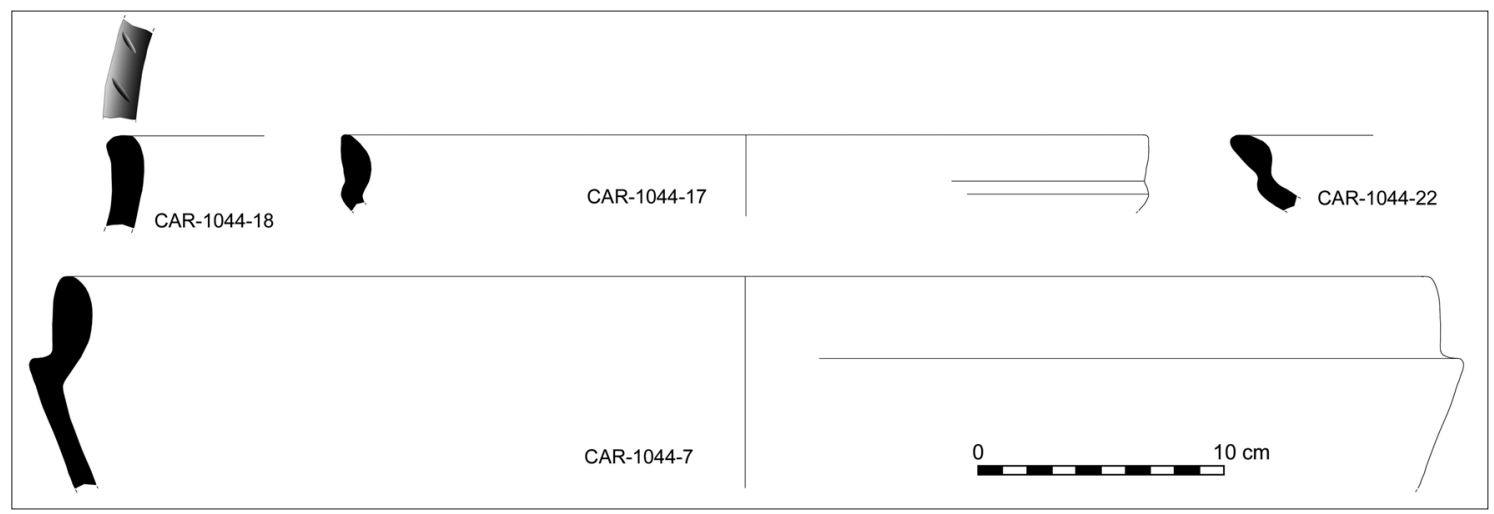

Figura 12. Grandes vasos de cerámica a mano de la UE 1044. Este depósito corresponde al momento de vida del Santuario V, el más antiguo, que se levanta en la segunda mitad del siglo IX a.C. La UE 1044 fue cortada por la fosa UE 2625, por lo que proporciona una fecha post quem para el barco, procedente de la UE 1022.

taba signos de edafización. Este rasgo puede hacerse extensivo a todos los rellenos diferenciados.

Los distintos vertidos que colman la fosa UE 2625 aparecen cortados por un nuevo hoyo de aproximadamente $1,10 \mathrm{~m}$ de diámetro, sección en U abierta y unos $0,30 \mathrm{~cm}$ de profundidad, relleno ahora por la UE 1211 . Este paquete se caracteriza por ser más heterogéneo que los anteriores, sobre todo porque está formado por numerosas bolsas de escasa potencia, discontinuas y con límites difusos, fruto de una deposición rápida, pero que de nuevo presentan abundantes restos óseos, conchas marinas y cerámica. A este contexto podría pertenecer asimismo otro depósito (UE 1027). Por encima de las UE 1022,1211 y 1027 se acumuló la UE 1021, asociada a la UE 1024, de características y cronologías similares a los sedimentos descritos anteriormente y fruto asimismo de una deposición rápida.

La fosa y los rellenos citados fueron amortizados por un vertido de color amarillento compuesto por margas disgregadas, registrado de forma puntual y discontinua (UE 1026,1030 y zona inferior de 1020 y de 1019). Las huellas de bioturbación sugieren que este nuevo paquete permaneció a la intemperie durante algún tiempo. Sobre él se detectó parte de una probable construcción en adobe, de la que apenas quedaban $5 \mathrm{~cm}$ de altura; tal estructura pudo formar la base de un muro de alineación noroeste-sureste $\left(340^{\circ}\right)$ y de $35 \mathrm{~cm}$ de anchura; junto a él se documentaron restos de un suelo de conchas marinas muy deteriorado (UE 1020 y 1019). Los elementos constructivos descritos formaron parte al parecer de estructuras arrasadas por las obras de las instalaciones del Tiro de Pichón que se realizaron en 1958, que también decapitaron las fosas y sus rellenos, hasta el punto de que algunos de los depósitos superiores aparecieron directamente bajo el pavimento del siglo XX (UE 1000). Este hecho, unido a la presencia de una serie de tuberías de desagüe y cimentaciones (UE 1001 y 1002) que aíslan la zona en que se hallan los ele- mentos descritos, impide establecer vínculos estratigráficos entre dicho sector y el resto del santuario. En consecuencia, dichas relaciones sólo se pueden proponer como hipótesis a partir de la cronología suministrada por los elementos arqueológicos del contexto.

Las fosas descritas se excavaron en un vertido previo de carácter heterogéneo (UE 1028) y en un estrato con rasgos edáficos que regulariza en parte la ladera oeste de este sector (UE 1044). Ambos conjuntos sedimentarios pueden fecharse a inicios del Hierro Antiguo. A su vez, la UE 1004 se superponía a una fase de ocupación (UE 1169) con pequeñas hogueras (UE 1168). Los materiales arqueológicos de todos estos estratos infrapuestos a la fosa UE 2625 pueden correlacionarse tipológicamente con los del edificio más antiguo (Santuario V), con lo que nuestro barco puede asignarse al Santuario IV. Por debajo aún de toda esta estratigrafía analizada aparece, inmediatamente encima de las margas terciarias del cabezo (UE 23), un nivel del Bronce Pleno que presenta en la superficie huellas de estabilización por intemperismo y abandono (UE 1018); mientras esta capa estuvo en formación se abrió una sepultura infantil que carecía de ajuar (UE 1170).

La estancia de la Sociedad de Tiro de Pichón en que se ubican estas unidades reseñadas fue la que seccionó la fosa interpretada en su día como fondo de cabaña por Maluquer y Carriazo. Recordemos que este elemento interfacial y sus rellenos han sido reexcavados y vueltos a documentar, en parte por primera vez, en las distintas campañas que desde 2002 se desarrollan en el yacimiento. Estos trabajos recientes han permitido reinterpretar aquel supuesto fondo de cabaña como una fosa de vertidos originados en el área sacrificial y cultual del santuario. Igualmente, han mostrado una evidente semejanza, por su carácter singular, entre los elementos exhumados por Carriazo y los recuperados en la zona que aquí estudiamos. El carácter sagrado o ritual del basurero puede 


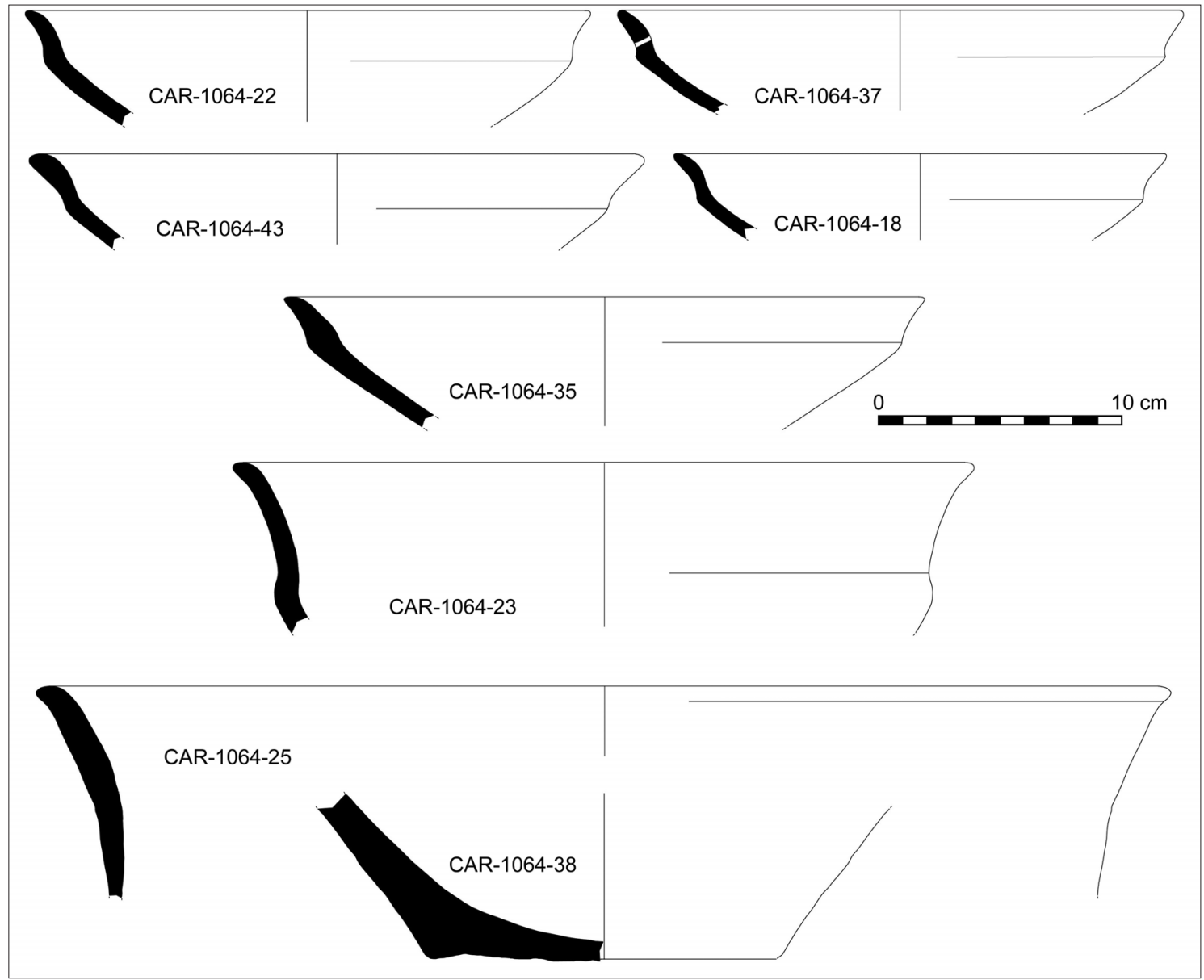

Figura 13. Recipientes de cerámica a mano de la UE 1064, nivel inmediatamente debajo del que contenía el híppos. Este depósito es el primero que empieza a colmatar la fosa UE 2625.

deducirse de su propio contenido: restos de sacrificios y de ofrendas y fragmentos de la vajilla y de elementos litúrgicos (Fernández Flores y Rodríguez Azogue 2005: 129). En el caso de las fosas y niveles en que se produjo el hallazgo de nuestro barco, se trataría de la misma función, pues corresponderían a otro vertedero destinado a los restos procedentes del área sacrificial y cultual. Su ubicación espacial, cercana al hipotético fondo de cabaña de Carriazo, refuerza esta interpretación, ya que todo ese sector presenta características similares a lo largo de las distintas fases del templo. El basurero contenido por la fosa UE 2625 habría estado funcionando a la vez que el Santuario IV. Por el contrario, el excavado parcialmente por Carriazo correspondería al Santuario III, si bien sobre sus últimos rellenos se abrirá una nueva oquedad para ocultar el tesoro en el momento de muerte del templo. El análisis tipológico de los restos cerámicos de este sector sugiere una cronología de mediados del siglo VIII a.C. como la más probable para la amorti- zación del barco en el basurero sagrado, ya como pieza rota e inservible (figs. 12-19).

\section{PARA CERRAR}

La importancia histórica de la réplica de barco hallada durante las recientes excavaciones en el Carambolo no estriba en las claves que pueda proporcionar para el estudio de las flotas que frecuentaron Tartessos. Ya hemos visto que esta reproducción no puede tenerse por una maqueta precisa de la realidad de un mercante, a pesar de que cuenta con elementos suficientes para deducir la modalidad de embarcación a la que hace referencia. Su presencia en el Carambolo implica en cambio un refuerzo tanto de la función desempeñada por el sitio en la Protohistoria de la Baja Andalucía como de la identificación étnica de la gente que lo fundó y usó. 


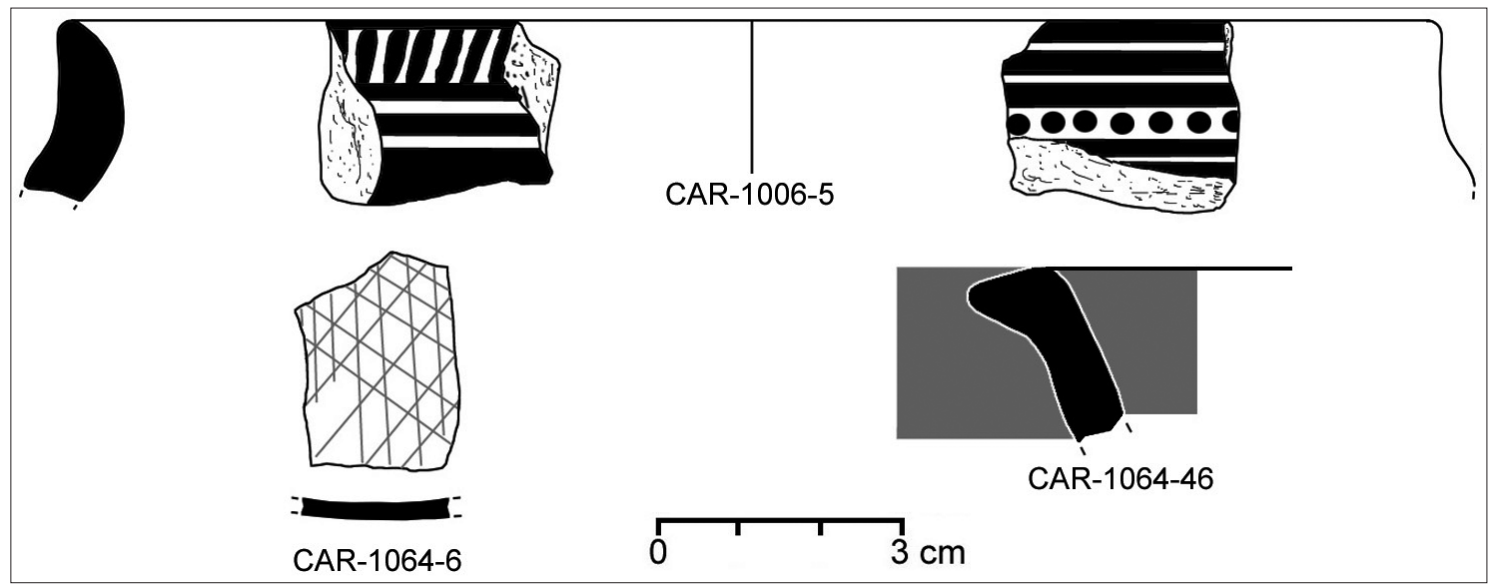

Figura 14. La cerámica griega geométrica (CAR-1064-5) proporciona una fecha de mediados del siglo VIII a.C. al depósito donde quedó amortizada (UE 1064). Este hallazgo ofrece una ajustada cronología tanto a este nivel como al que contenía el barco, el que se le superpone (UE 1022). En la UE 1064 se documentaron además vasijas a mano con decoración pintada (CAR-1064-6) y cerámica a torno fenicia de barniz rojo (CAR-1064-46).

De sobras se conoce que, en casi todo el Mediterráneo, las reproducciones a escala de navíos, hechas en

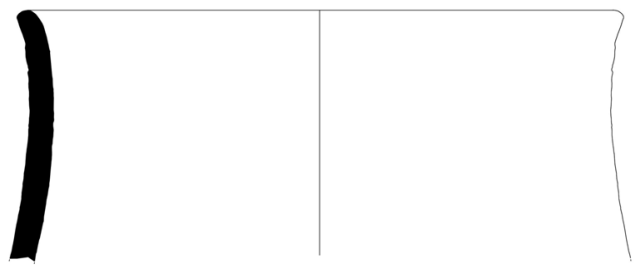

CAR-1022-35

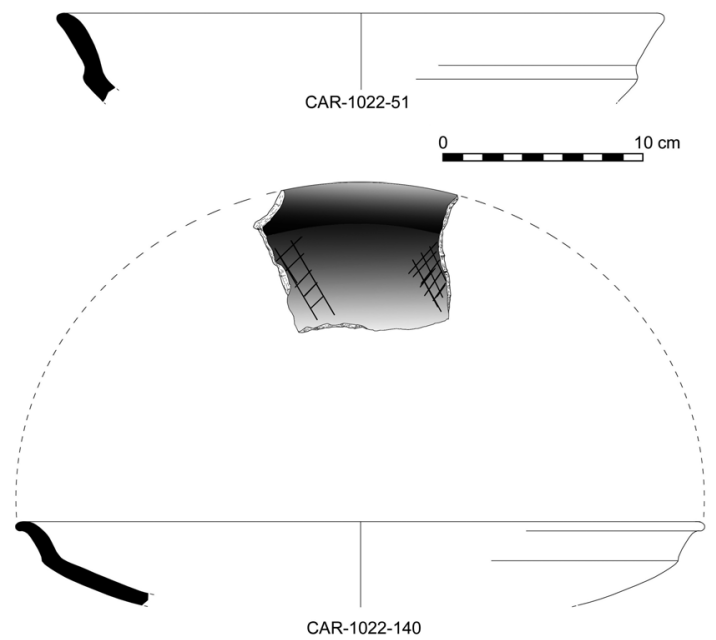

Figura 15. La nave ritual del Carambolo apareció amortizada en un depósito que contenía fragmentos de grandes recipientes de cerámica a mano, algunos con decoración bruñida (CAR-1022-140). madera, en metal o en cerámica, aparecen en altísimo porcentaje en contextos cultuales. En el mundo egipcio, y por la simbología que relacionó a las embarcaciones con los movimientos de los astros en la bóveda celeste y a éstos con el mundo de la muerte, tales ejemplos se constatan sobre todo en ambientes funerarios (cf., por ejemplo, Casson 1994: lám. III). Pero en otras muchas zonas, especialmente en Chipre y Cerdeña por ejemplo, los lugares de aparición más comunes son también los santuarios, sobre todo los consagrados a divinidades relacionadas con la navegación. Esta circunstancia refuerza la hipótesis de que el Carambolo fue, durante todos sus momentos de vida entre los siglos IX y VI a.C., sólo un promontorio dedicado a Astarté, cuya vinculación a la diosa fenicia patrona y protectora de los navegantes se llevó a cabo mediante la construcción de un suntuoso templo y sus dependencias anejas.

El carácter fenicio del barco, indiscutible gracias a su mascarón en forma de cabeza de caballo, puede ponerse en relación directa con la iconografía oriental sobre los barcos que, en la primera mitad del primer milenio a.C., usaban las marinas cananeas de las ciudades costeras del actual Líbano. Como herencia de aquella tradición marinera, el híppos acabó por convertirse en el barco cuya nacionalidad era de más fácil identificación (Guerrero 1998: 76). Asimilando la parte al todo como cualquier sinécdoque, su prótomo logró dar nombre a la embarcación, aunque Plinio (N.H. VII, $57^{15}$ ) relacionó el término con un supuesto

15 Onerariam Hippus Tyrios invenit, lembum Cyrenenses, cymbam Phoenices, celetem Rhodii, cercurum Cyprii (tomado de Torr 1964: 114). 


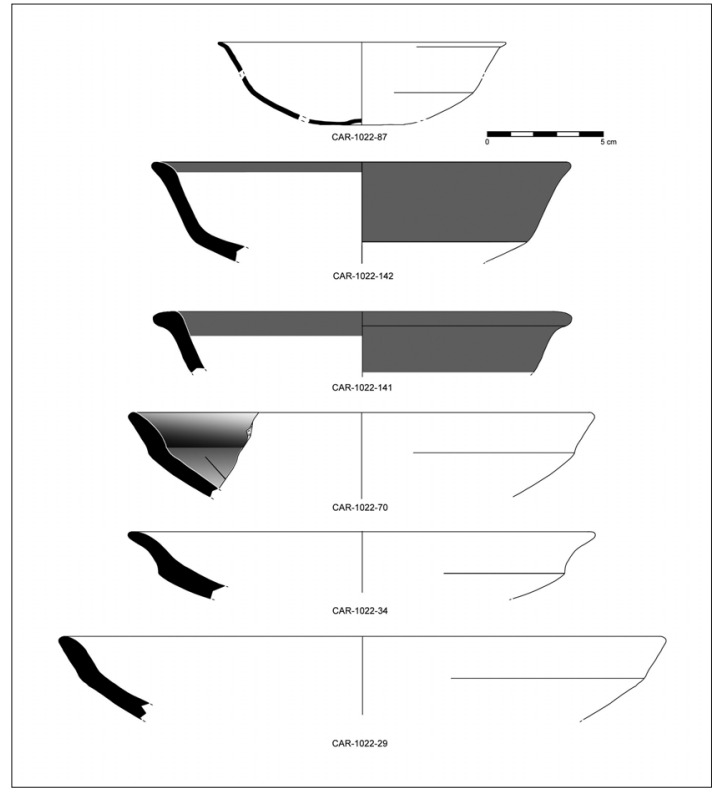

Figura 16. Materiales cerámicos que acompañaban al barco en la UE 1022: recipientes a mano bruñidos (CAR-1022-87, CAR-1022-34 y CAR-1022-29), cuenco carenado a mano con decoración bruñida (CAR-1022-70) y cerámica fenicia de barniz rojo (CAR-1022-142 y CAR-1022-141). Los vasos fenicios permiten datar el depósito en el siglo VIII a.C.

inventor tirio llamado Hippos (Aubet 1994: 156), una especie de ingeniero que podemos dar por legendario ya que dicho antropónimo no es conocido en la tradición lingüística semita (Luzón 1888: 447). Pudieron ser estos navíos, por tanto, los usados en parte para el desplazamiento de la colonización fenicia a Occidente y para sus transacciones mercantiles, y no sólo unas pequeñas barcazas destinadas al comercio local y a la pesca. De hecho, la idea tan extendida de que los híppoi eran barcos humildes usados por gente pobre para pescar puede considerarse una consecuencia de la evolución tardía de los modelos más arcaicos, según la cual habrían desaparecido ya en época romana los híppoi de más tonelaje; porque la noticia de que se trataba de una pequeña embarcación pesquera usada por los gaditanos en los bancos marroquíes sólo la conocemos por Estrabón (II, 3, 4) ${ }^{16}$. En cambio, los bajorrelieves del palacio de Sargón II en Khorsabad, mucho más antiguos como hemos indicado ya, enseñan barcos cargados de grandes troncos de madera y bien dotados de tripulación, aunque ésta lógicamente

\footnotetext{
${ }^{16}$ Aunque este empleo ha sido generalmente admitido de forma casi exclusiva en las obras más generales sobre la navegación antigua (cf. Rougé 1975: 153), las numerosas gateras del barco del Carambolo levantan ciertas dudas al respecto.
}

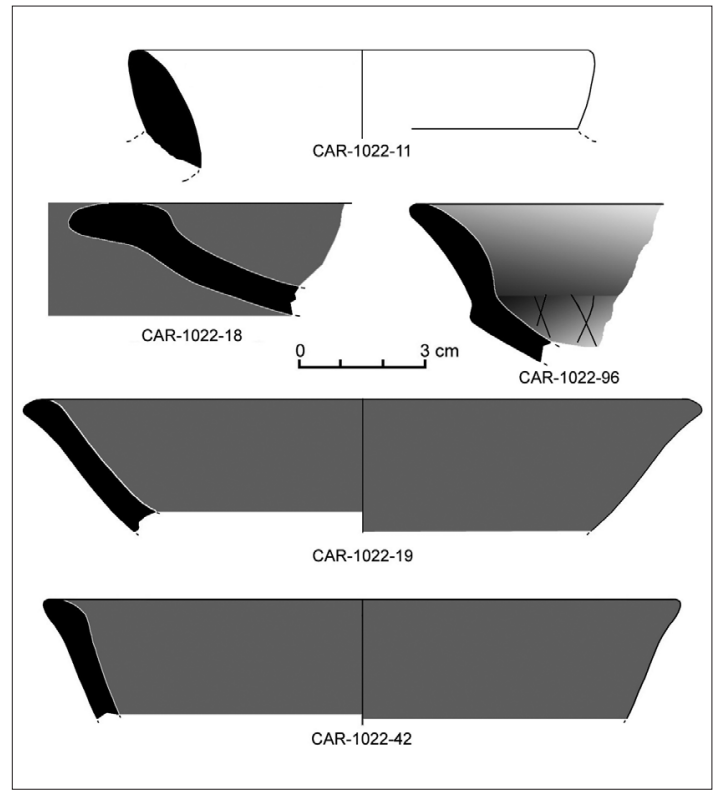

Figura 17. Materiales cerámicos del siglo VIII a.C. que acompañaban a la embarcación en la UE 1022: ánfora, posiblemente de tipo ovoide (CAR-1022-11), cerámica fenicia de barniz rojo (CAR-1022-18, CAR-1022-19 y CAR-1022-42), recipiente a mano con decoración bruñida (CAR-1022-96).

aparece en mayor número en el caso de los navíos de guerra representados en la escena que narra la huida desde Tiro del rey sidonio Luli y de su gente. Es normal que esto sea así porque la principal carga que debe llevar un barco de guerra, aun teniendo espolón de ataque, es un nutrido grupo de remeros que acelere su velocidad y le proporcione agilidad en la evolución de sus movimientos en caso necesario (Bartoloni 1988a: 75; 1988b: 137) ${ }^{17}$, personal del ejército con su panoplia, es decir, infantería (Rougé 1975: 106), e impedimenta bélica, como conocemos bien desde momentos anteriores a la expansión fenicia gracias al relieve de la victoria de Ramsés III sobre los pueblos del mar, en la que la flota egipcia sirve sobre todo para transporte de la tropa (Casson 1991: 33-35). A ello se une, en el caso del panel asirio, que se trata del relato de una migración, con su cuota correspondiente de hombres, mujeres y niños que acompañan a Luli al exilio. Deducimos de todo este razonamiento, por tanto, que los grandes cargueros que hacían las largas singladuras entre Oriente y Occidente, también pudieron disponer de un akrotérion en forma de cabeza de caballo, con-

${ }^{17}$ Los vasos griegos de estilo geométrico muestran ya de forma explícita este tema (cf. Casson 1971: 71-74 y, especialmente, fig. 74). 


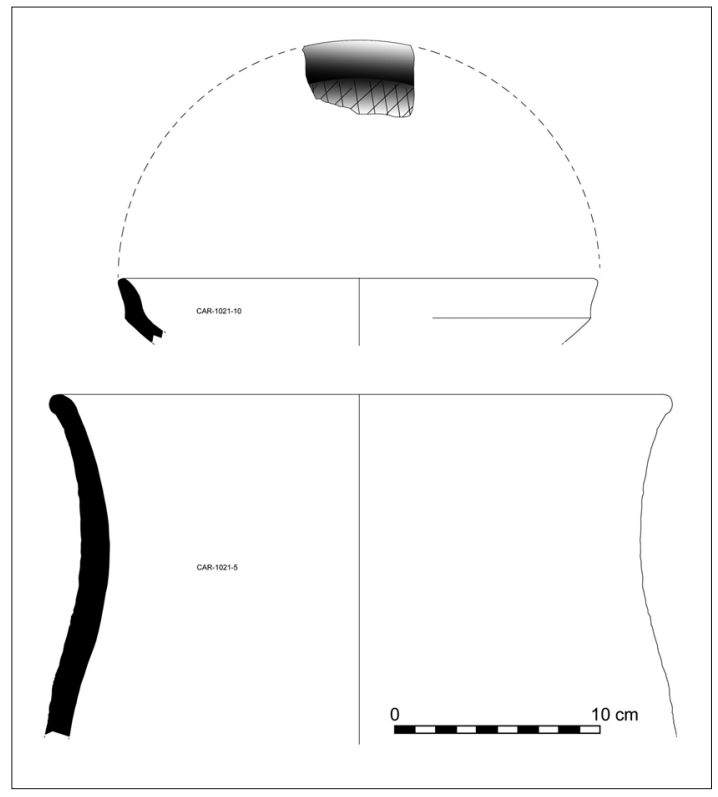

Figura 18. Cerámica a mano de la UE 1021: cuenco carenado con decoración brunida (CAR-1021-10) y vaso de perfil en S (CAR-1021-5). La UE 1021 colmata la fosa UE 2625 y se superpone a la que contenía la nave (UE 1022); sus materiales son semejantes a los que acompañaban al barco, con lo que certifican que éste quedó amortizado posiblemente a mediados del siglo VIII a.C.

viniéndoles por tanto el nombre de híppoi. Esto explica que fuera uno de estos barcos, identificado como tipo insignia de la flota de Gadir, el que según Estrabón (II, 3, 4) encontró la exploración de las costas africanas emprendida hacia 118 a.C. por el marino griego Eudoxo. Como el prótomo -akrotérion en la vieja tradición helénica que arranca al menos del segundo milenio a.C.- llegó a convertirse en una especie de bandera para la identificación nacional de los barcos, Eudoxo, que cargó hasta Alejandría con el mascarón de aquel barco, pudo saber al llegar a puerto que pertenecía a una nave de los fenicios gaditanos (Luzón 1988: 445-446).

De acuerdo con una línea de investigación desarrollada en torno al Caballo de Troya, algunos autores han defendido que dicho animal de madera, que los griegos dejaron a los troyanos como regalo envenenado, no sería más que una nave con prótomo de caballo sobre su codaste y en cuyas bodegas se habrían escondido unos cuantos guerreros helenos (Torr 1964: 114). Esta hipótesis parece muy verosímil dada la terminología náutica con que se describe a veces el mito y la existencia en la Antigüedad de autores que así lo afirman categóricamente, pero, a diferencia de lo que sostiene Luzón (1988: 454-455), creemos improbable que dicha tradi-

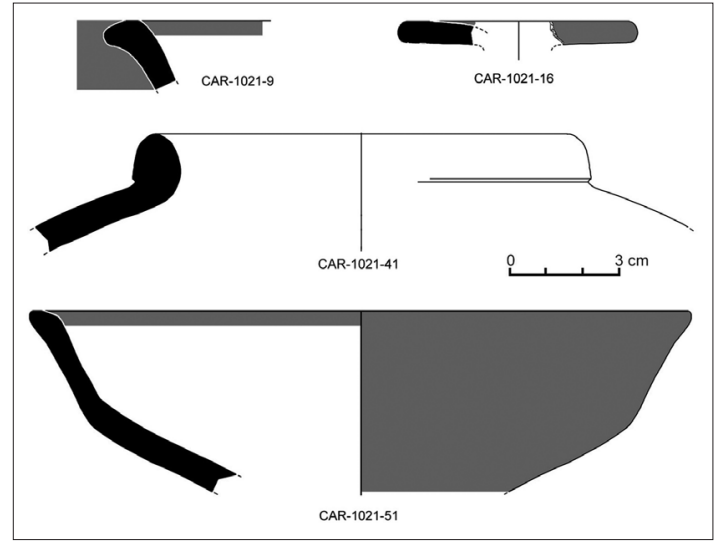

Figura 19. Cerámica a torno de la UE 1021: escudillas de barniz rojo (CAR-1021-9 y CAR-1021-51), boca de oinochoe de barniz rojo (CAR-1021-16) y borde de ánfora

(CAR-1021-41). Estos materiales fenicios suministran a la UE 1021 una datación del siglo VIII a.C., cronología que sella el depósito en el que apareció el híppos (UE 1022).

ción, caracterizada por usar barcos con cabeza de caballo como mascarón de proa, llegara a la Península Ibérica antes de la expansión cananea del primer milenio a.C., porque todo lo que se ha dicho de la precolonización fenicia en relación con Tartessos está basado en datos científicos muy inseguros, hasta el punto de que aconsejan descartarla por completo (Escacena e.p.). Esto no niega que otros barcos mediterráneos más antiguos frecuentaran las costas del mediodía ibérico, y que esas embarcaciones dispusiesen además de mascarones de proa con formas de cabezas de animales. Eso es, al menos, lo que sugiere el barco con cabeza de toro en la proa representado en un cuenco campaniforme del yacimiento almeriense de Los Millares (Molina 2005: 94). En cualquier caso, la inexistencia de barcos con cabeza de caballo en la proa, o con nombres que tengan que ver con este animal, en el mundo ugarítico del segundo milenio a.C. (cf. Vita 2000), apoya la propuesta de Luzón (1988) de que los fenicios tomaron el tipo del Egeo. Parece probable que esta transmisión se hiciera a través de Chipre, donde el mundo helénico y el cananeo entraron en contacto ya en el segundo milenio a.C. (Ruiz de Arbulo 1998: 33).

Nuestra conclusión puede parecer en principio un poco contradictoria, ya que, a pesar de que creemos encontrarnos claramente ante un híppos, no podemos asimilar el ejemplar del Carambolo con claridad a ninguno de los dos buques fenicios propuestos tradicionalmente por la investigación. A favor de su asimilación al híppos clásico estaría el hecho indudable de su mascarón en forma de cabeza de caballo, pero en contra de esta idea habla el excesivo número de remos para considerarlo un barco destinado sólo a navegacio- 
nes costeras y de cabotaje. Sobre este aspecto las opiniones son ambiguas. De una parte, se sostiene que el tipo pudo disponer de hasta veinte o treinta remeros para las empresas mayores (Guerrero 1998: 77), mientras que otros investigadores, basándose en el relieve de las puertas de Balawat ya mencionado, proponen no mucho más de dos tripulantes (Aubet 155-156). De hecho, se ha llegado a afirmar que "los remos trabajarían fijos en toletes o chumaceras sobre la regala, y nunca a través de gateras como ocurre en las birremes y trirremes" (Guerrero 1998: 78), lo que no cuadra evidentemente con el ejemplar del Carambolo ni con otras reconstrucciones de lo que eran los híppoi. Así, en la maqueta que se expone en el Museo Marítimo Nacional de Haifa, esta modalidad de mercante fenicio cuenta con una fila de remos a cada banda que traspasan la borda por gateras (cf. De Graeve 1981: fig. 129). Si el modelo híppos representó algo más que una simple barcaza para desplazamientos de cercanía, como sugiere la referencia ya citada al naufragio hallado por Eudoxo en las costas atlánticas africanas, para las que harían falta buques de mayor calado, convendría revisar las atribuciones a las tradicionales capacidades de carga asignadas a cada tipo de embarcación, ya que nada impide que el modelo gaulós, tenido entre los que más tonelaje pudieron transportar de la marina fenicia (Aubet 1994: 156), dispusiera también de prótomos en forma de cabeza de caballo, en cuyo caso podría ser asimilado al híppos. De hecho, también J. Alvar (1981: 53), a pesar de que duda de la noticia referida por Estrabón, sostiene que debió ser un barco de más tonelaje que el normalmente asumido para el híppos. En cualquier caso, algunas propuestas de reconstrucción de los buques de tipo gôlah se han hecho con cabeza de caballo en la proa (cf. Díes Cusí 1994: fig. 5; 2004: 60). Pero también se ha dicho que los híppoi sirvieron como naves de exploración de nuevos territorios a los que extender la colonización (Guerrero 1998: 61), y que podían enfrentarse a situaciones apuradas y a vientos contrarios arriando velas y usando la propulsión a remo (Guerrero 2004: 87), lo que sugiere que pudieron estar dotados de una tripulación más numerosa que los dos o tres remeros que normalmente se aceptan cuando se piensa en que fueran sólo pequeñas embarcaciones de cercanía. Precisamente por su tamaño no muy grande, los barcos de Mazarrón podrían pertenecer a estos tipos destinados al transporte de pequeña distancia, y en cambio en ellos no existen señales del uso del remo, sólo del impulso a vela, lo que se ha deducido con facilidad gracias a que se ha conservado la carlinga del mástil en el centro de la quilla (Negueruela 2004: 235). Los paralelos más parecidos para las gateras del barco del Carambolo corresponden de momento a los orificios para los remos que presenta un gaulós de terracota procedente de Amathus, en Chipre, fechado en los siglos VI-V a.C. El hecho de que esta miniatura no lleve cubierta ha sido interpretado como una licencia de quien la fabricó a fin de mostrar el interior de la nave (Guerrero 1998: 74), lo que sería razonable admitir si no fuera porque el barco del Carambolo también carece de ella. Los problemas para una identificación definitiva aumentan en este caso si es un híppos el barco birreme desde el que Asurbanipal fue representado cazando leones en un relieve del palacio de Kuyunjik (Barnett 1958: 220). En este caso, la fila superior de remos pasa por encima de la borda, mientras que los de la inferior atraviesan el casco por sendas gateras (De Graeve 1981: 57 y fig. 67). La nave de esta escena cuenta con quince remeros por banda (Alvar 1981: 53 y fig. 25). Para solventar tales problemas de asignación a un tipo determinado, se ha recurrido incluso a dividir el modelo en dos variantes, distinguiendo entre el híppos propiamente dicho y sus formas derivadas (De Graeve 1981: 123-128), lo que parece de nuevo una solución ad hoc para adaptar los datos a esquemas mentales preconcebidos.

La presencia, en fin, de una embarcación de este tipo en un santuario dedicado a Astarté refuerza el carácter fenicio del Carambolo según ya hemos adelantado. Además, en contra de quienes se empeñan en seguir situando este sitio en las tierras interiores de Tartessos, consolidaría la idea, afianzada en diversos estudios geológicos (cf. Gavala 1959; Menanteau 1982, Arteaga y otros 1995) de que hasta Sevilla al menos -si no hasta Ilipa (Alcalá del Río)- podían llegar, como aún hoy, las embarcaciones de gran calado -tipo gaulós-, las mismas que servían para hacer las rutas marítimas entre Oriente y Occidente en calidad de grandes mercantes. Con razón, ya F. Collantes de Terán (1977: 37-54) sostuvo en su día que la razón de ser de la creación de Hispalis (la Spal de época tartésica) fue precisamente su estratégico emplazamiento para la navegación por el paleoestuario del Guadalquivir. Si desde un análisis filológico el topónimo Spal puede ser considerado de origen fenicio totalmente (Díaz Tejera 1982: 20; Lipinski 1984: 100) o en parte (Correa 2000), la hipótesis más verosímil sobre la fundación de Sevilla pasa por atribuirla a los colonos cananeos del primer milenio a.C., los mismos que levantarían a la vez el santuario de Astarté en una de las colinas más elevadas que la meseta del Aljarafe ofrecía justamente en el frente de poniente, al otro lado de la ría bética. Visto lo cual, mucho empecinamiento será necesario para seguir viendo en el Carambolo un asentamiento de los indígenas de Tartessos, porque esta otra hipótesis tendrá que luchar contra un cúmulo de datos que hablan de su filiación fenicia, al que se une ahora el barco aquí estudiado. ¿Cómo se comprende, si no, que, de ser esta réplica un exvoto, la población autóctona asignara el cuida- 
do de sus naves a dioses extranjeros, y que lo hiciera además ofreciendo en el templo un barco votivo de cerámica que imitaba también modelos foráneos?

Después de este hallazgo, y en correspondencia con los estudios geomorfológicos ya citados que sitúan el paleoestuario del Guadalquivir entre las antiguas ciudades de Caura (Coria del Río) e Ilipa (Alcalá del Río), el Carambolo puede tenerse sin lugar a dudas por santuario costero, a pesar de que hoy se encuentra a casi ochenta kilómetros del litoral. En este recinto sagrado dedicado a Astarté se han constatado, además, conocimientos astronómicos de cierta importancia, deducidos de la orientación helioscópica del templo y de sus altares (Escacena 2006: 16-18). Por esta razón el Carambolo cobra todo su valor como lugar de encuentro entre los pilotos de las embarcaciones y los sacerdotes más peritos en el conocimiento del cielo. No en balde, después de una etapa prehistórica en que los marinos navegaron sin cartas ni instrumentos (Arnaud 2005: 50), y que acudieron a las aves como ayuda en la orientación náutica (Hornell 1946; Luzón y Coín 1986; Guerrero 1993: 19-26), se atribuye a los fenicios la introducción en el Mediterráneo de la navegación de altura guiada por las estrellas (Plinio N.H. VII, 209; Estrabón I, 1, 6), de donde le vino en la Antigüedad a la principal guía semita de las singladuras nocturnas, la constelación de la Osa Menor, el nombre de «Estrella Fenicia» (Bartoloni 1988a: 72) ${ }^{18}$. Además, si en el Carambolo se podía conseguir un cabal conocimiento del comienzo del verano, gracias sobre todo a que el eje de su altar en forma de piel de toro apuntaba en dirección este al orto solar del solsticio de junio, dicho control del tiempo cronológico permitiría estar al día en cuanto al dominio de las fechas que marcaban el principio y el final de la temporada apta para la navegación, que -se supone- coincidía básicamente con el estío (Alvar 1981: 75-76).

Si los buques de tipo gaulós estuvieron asociados a grandes empresas comerciales en las que los armadores pudieron estar representados por el propio estado en el caso fenicio personalizado en los templos de Melqart (Guerrero 1998: 86)-, la presencia del híppos del Carambolo en un santuario de Astarté sugiere un tratamiento similar para estas otras naves más versátiles. Desde el Fani Prominens de Avieno (O.M. 261), cuya

\footnotetext{
${ }^{18}$ Frente a esta tradición, los griegos prefirieron la fijación de los derroteros a través de la Osa Mayor. Por estar más cerca del Polo Norte, parece que la Osa Menor pudo ofrecer más precisión a los fenicios en la orientación náutica, aunque disponía de menos luminosidad que su hermana. En cualquier caso, la posición de dichas constelaciones hacia el 500 a.C. era distinta de la actual, de forma que la Estrella Polar no coincidía entonces con la prolongación del eje de rotación de la Tierra (Medas 2004: 45-46).
}

identificación con el Carambolo parece cada vez más evidente, pero sobre todo desde el puerto de Spal (Sevilla) situado enfrente, los híppoi pudieron bogar Guadalquivir arriba al menos hasta la cabecera del estuario, donde en la ciudad de Ilipa se ubicaba otro grupo colonial fenicio ${ }^{19}$. En cambio, aguas abajo y a sólo unos diez kilómetros del Carambolo, en las antiguas bocas del río, se abría ya, desde Caura hacia el sur, el Sinus Tartesii (Avieno, O.M. 265), la gran ensenada que precedía al Atlántico y desde la que se iniciaban los derroteros hacia Gadir y el Mediterráneo, en dirección este, y hacia Portugal o África en sentido oeste. Pero también para estas singladuras más arriesgadas era apto el híppos. Y, aunque su capacidad de carga era al parecer menor que la del gaulós, el valor de ésta superó seguramente con mucho a la de los grandes buques mercantes. Entre dicha mercancía se ha citado con frecuencia el vino (Guerrero 1998: 77), lo que en nuestro caso está certificado por un ánfora para los apreciados caldos de Quíos proveniente de Caura (Belén 1993: 44-46 y fig. 6, 2).

Por los múltiples ejemplos similares conocidos en santuarios del mundo mediterráneo, la presencia de esta réplica de barco en el Carambolo viene a consolidar una de las hipótesis con las que abríamos este artículo, aquella que vio siempre en el yacimiento suficientes elementos cultuales como para creerlo un importante centro ceremonial. En este contexto sagrado, la interpretación más tradicional, deducible en parte de otros hallazgos similares repartidos por el Mediterráneo, reconocería en el objeto de nuestro estudio una ofrenda votiva. Desde tal lectura, la embarcación del Carambolo vendría a representar el agradecimiento a la divinidad, por parte de uno o varios fieles, de un favor que habían recibido o solicitado. Sin embargo, no queremos finalizar este trabajo sin apuntar otra hipótesis verosímil aunque tal vez

\footnotetext{
19 Para la época tartésica o fase arcaica de la colonización fenicia en el mediodía ibérico, lo que hoy es vega del Guadalquivir entre Alcalá del Río y el comienzo de la comarca de las Marismas constituía una ancha llanura de inundación. En ella comenzaban a dibujarse los meandros históricos del río, entonces sólo como grandes caños de marea que posiblemente eran rebasados por el agua durante la pleamar (Borja y Barral 2005: 19). Esta circunstancia, unida al hecho de que los híppoi no eran navíos de excesiva obra viva, permitía que la navegación fenicia pudiera alcanzar el fondo del estuario sin necesidad de hacer trasbordo en puntos intermedios entre el mar e Ilipa, por lo menos en momentos de aguas altas. Sin embargo, como en época romana dicha llanura se había colmatado de aluviones y la desembocadura se había desplazado ya hasta las cercanías de Lebrija (Arteaga y otros 1995), las mercancías que remontaban el Betis debían de cambiar en Hispalis a barcos menores (Chic 1990: 22). Estrabón (III, 2, 3) dio cuenta precisa de estos detalles, que hicieron de la Hispalis romana el puerto de embarque de los excedentes agrícolas de la Bética (Parodi 2001: 174).
} 
menos cómoda, la que vería en dicha nave de cerámica una representación del barco astral en el que los dioses atraviesan a diario la bóveda celeste. Como se sabe, esta función es bien conocida en el mundo egipcio, del que tanto se impregnó el imaginario religioso fenicio. En el país del Nilo, las divinidades del cielo navegan todas las jornadas por el firmamento en sus correspondientes barcas sagradas, en las que realizan tanto la singladura nocturna como la diurna. Pero esta creencia no fue exclusiva de Egipto. Gracias al denominado "disco de Nebra", una representación del universo visible plasmada en una placa circular de bronce procedente de Sajonia, conocemos su existencia en la Europa prehistórica del segundo milenio a.C. (Meller 2004). Igualmente, es posible que aluda ya a lo mismo la decoración simbólica que exhiben unos cuencos de cerámica calcolítica del sureste hispano (cf. Martín y Camalich 1982: fig. 5d). En consecuencia, esta otra hipótesis incrementaría aún más el carácter sagrado del híppos del Carambolo, y lo situaría al mismo nivel que otras muchas representaciones de la barca astral (solar o no) conocidas en el Mediterráneo oriental durante el primer milenio a.C. En los centros de culto fenicios del mediodía ibérico son abundantes precisamente las referencias a cuestiones astronómicas, que se manifiestan en el Carambolo de forma especial a través de la orientación helioscópica del propio santuario y de su altar en forma de piel de toro. Con esta interpretación, el barco del Carambolo no sería tanto un exvoto propiamente dicho cuanto un objeto sagrado más del ajuar litúrgico del templo. Se explicaría así que, a diferencia de casi todas las embarcaciones votivas conocidas en los santuarios de esa época, la del Carambolo no muestre la simetría lateral típica de una nave genuina, es decir, que las gateras para los remos sólo aparezcan en una de las bordas. Al contrario que los auténticos exvotos, el híppos del Carambolo no se habría elaborado para imitar con fidelidad una embarcación real usada por marineros y/o comerciantes fenicios en sus actividades económicas. Su diseño presupone más bien la idea preconcebida de algo que va a ser expuesto en un lugar muy visible del santuario. Que su encargo al alfarero fuera una acción llevada a cabo por el propio templo, o que estemos en cambio ante un regalo privado a la divinidad, son ya extremos de imposible aclaración con los datos arqueológicos con que hasta hoy contamos. Pero sí podemos adelantar que la concepción de esta nave, y su gran tamaño en relación con la mayor parte de los exvotos conocidos, sugieren que no nos encontramos en realidad ante un objeto votivo, sino ante una parte del ajuar litúrgico usado en los ritos que se celebraban en el santuario. De ser cierta esta hipótesis, los fenicios emigrados a Tartessos habrían reproducido en Occidente con bastante fidelidad, como es además lo esperable, las creencias y los cultos que se practicaban en sus metrópolis de procedencia. Si éstas fueron en parte similares a lo que conocemos del mundo egipcio, el híppos del Carambolo no sería más que una barca sagrada, elemento de capital importancia en los templos del país del Nilo. Como es bien conocido, en éstos existía una capilla, de especial significado en los santuarios solares, destinada precisamente a la barca sagrada. Como puede verse en múltiples manifestaciones del arte faraónico, por ejemplo en el llamado "techo astronómico" del Rameseum (Lull 2004: 141), sobre esa barca se representa a los dioses en sus manifestaciones astrales, y sobre ella navegan siempre estrellas y constelaciones. Es más, subida sobre unas andas, se convierte en determinadas ceremonias en la peana procesional por antonomasia. Tal vez sea de esta forma como puedan comprenderse mejor algunas referencias textuales que identifican la montaña sagrada de Baal con el término usado para "barco", la consagración de una nave a Melqart en Tiro transmitida por Arriano o la imagen plasmada en un anillo en la que se representó, sobre las olas, una embarcación que porta en su centro el disco solar (Ruiz Cabrero 2007: 99, 101 y 121), escena que remitiría sólo al mundo egipcio si no fuera por la inscripción fenicia que la acompaña.

Esta hipótesis, que podría venir reforzada por otros aspectos solares constatados en el Carambolo, no pretende más que abrir nuevos caminos de investigación a los ya más conocidos acerca de los usos simbólicos de los barcos en ambientes fenicios, entre los que se han trabajado sobre todo la vinculación al mundo del más allá y al rito molk. No obstante, convendría tener presente para el futuro también estos otros aspectos en tanto que en el santuario recibió culto la diosa Astarté, como se desprende del exvoto de bronce encontrado allí mismo (Bonnet 1996: 128-130; Bonnet y Xella 1996). Como se conoce de sobras, esta divinidad estuvo fuertemente vinculada a las creencias funerarias. Es más, su asimilación a la Isis egipcia a partir sobre todo de la primera mitad del primer milenio a.C. (Scandone 1983: 405-406; Bonnet 1996: 22), permitiría igualmente abrir otra puerta a la interpretación del barco del Carambolo como pieza de culto vinculada a un posible precedente de la fiesta primaveral del Navigium Isidis o Ploiaphesia, conocida sobre todo a partir de época helenística y que incluía una procesión con una lámpara en forma de nave (Ruiz de Arbulo 2006: 206-207).

\section{BIBLIOGRAFÍA}

ALMAGRO-GORBEA, M. (1977): El Bronce Final y Periodo Orientalizante en Extremadura (Bibliotheca Praehistorica Hispana XIV). CSIC, Madrid.

ALVAR, J. (1981): La navegación prerromana en la Península Ibérica: colonizadores e indígenas. Universidad Complutense, Madrid. 
AMORES, F.; ESCACENA, J.L. (2003): "De toros y de tesoros: simbología y función de las joyas de El Carambolo", en A. García-Baquero y P. Romero (ed.), Fiestas de toros y sociedad: 41-68. Universidad de Sevilla, Sevilla.

ARKELL, A.J. (1959): "Early shipping in Egypt", Antiquity 33: 52-53.

ARNAUD, P. (2005): Les routes de la navigation antique. Itinéraires en Méditerranée. Errance, Paris.

ARTEAGA, O.; SCHULZ, H.D.; ROOS, A.M. (1995): "El problema del 'Lacus Ligustinus'. Investigaciones geoarqueológicas en torno a las Marismas del Bajo Guadalquivir", Tartessos 25 años después, 1968-1993, Jerez de la Frontera: 99-135. Ayuntamiento de Jerez de la Frontera, Jerez de la Frontera.

AUBET, M.E. (1992-93): "Maluquer y El Carambolo", Tabona VIII (II): 329-349.

AUBET, M.E. (1994): Tiro y las colonias fenicias de Occidente. Crítica, Barcelona.

BARNETT, R.D. (1958). "Early shipping in the Near East”, Antiquity 32 (128): 220-230.

BARTHÉLEMY, M. (2000): "El comercio fluvial fenicio en la Península Ibérica", en M.E. Aubet y M. Barthélemy (ed.), IV Congreso Internacional de Estudios Fenicios y Púnicos, vol. I: 291-297. Universidad de Cádiz, Cádiz.

BARTOLONI, P. (1988a): "Le navi e la navigazione", en S. Moscati (dir.), I Fenici: 72-77. Fabbri, Milano.

BARTOLONI, P. (1988b): "L'esercito, la marina e la guerra", en S. Moscati (di.), I Fenici: 132-138. Fabbri, Milano.

BARTOLONI, P. (1995): "Navires et navigation", en V. Krings (ed.), La civilisation phénicienne et punique. Manuel de recherche: 282-289. E.J. Brill, Leiden.

BELÉN, M. (1993): "Mil años de historia de Coria: la ciudad prerromana", en J.L. Escacena (coord.), Arqueología de Coria del Río y su entorno, en Azotea 11-12 (Monográfico de la Revista de Cultura del Ayuntamiento de Coria del Río): 35-60.

BELÉN, M.; ESCACENA, J.L. (1997): "Testimonios religiosos de la presencia fenicia en Andalucía occidental", Spal 6: 103-131.

BELÉN, M; ESCACENA, J.L. (2002): "La imagen de la divinidad en el mundo tartésico", en E. Ferrer (ed.), Ex Oriente Lux: Las religiones orientales antiguas en la Península Ibérica: 159-184. Universidad de Sevilla, Sevilla.

BLANCO, A. (1968): "Los primeros ensayos de representación plástica de la figura humana en el arte español", España en las crisis del arte europeo (coloquio celebrado en conmemoración de los XXV años de la fundación del CSIC). Instituto "Diego Velázquez", Madrid.
BLANCO, A. (1979): Historia de Sevilla. I (1) La ciudad antigua (Desde la prehistoria a los visigodos). Universidad de Sevilla, Sevilla.

BONNET, C. (1996): Astarté. Dossier docummentaire et perspectives historiques. (Contributi alla Storia della Religione Fenicio-Punica II). Consiglio Nazionale delle Ricerche, Roma.

BONNET, C.; XELLA, P. (1996): "L'identité d'Astarté, h.r", Alle soglie della classicità. Il Mediterraneo tra tradizione e innovazione. Studi in onore di Sabatino Moscati (Acquaro, ed.), vol. I: 29-46. Istituti Editoriali e Poligrafici Internazionale, Pisa y Roma.

BONSOR, G. (1899): Les colonies agricoles pré-romaines de la vallée du Bétis (Revue Archéologique XXXV). Ernest Léroux, Paris.

BORJA, F.; BARRAL, M.A. (2005): "Evolución histórica de la vega de Sevilla. Estudio de geoarqueología urbana", en A. Jiménez (ed.), La catedral en la ciudad (I). Sevilla, de Astarté a San Isidoro: 6-36. Aula Hernán Ruiz, Sevilla.

CARRIAZO, J. de M. (1970): El tesoro y las primeras excavaciones en «El Carambolo» (Camas, Sevilla) (Excavaciones Arqueológicas en España 68). Ministerio de Cultura, Madrid.

CARRIAZO, J. de M. (1973): Tartesos y el Carambolo. Ministerio de Educación y Ciencia, Madrid.

CASSON, L. (1971): Ships and seamanships in the ancient world. Princeton University Press, Princeton.

CASSON, L. (1991): The ancient mariners. Seafarers and sea fighters of the Mediterranean in ancient times. Princeton University Press, Princeton.

CASSON, L. (1994): Ships and seafaring in ancient times. British Museum Press, London.

CASTRO, P.V.; LULL, V.; MICÓ, R. (1996): Cronología de la prehistoria reciente de la Península Ibérica y Baleares (c. 2800-900 cal ANE) (BAR Intern. Ser. 652). Oxford.

CHIC, G. (1990): La navegación por el Guadalquivir entre Córdoba y Sevilla en época romana. Gráficas Sol, Écija.

COLLANTES DE TERÁN, F. (1977): Contribución al estudio de la topografía sevillana en la Antigüedad y en la Edad Media. CSIC, Sevilla.

CORREA, J.A. (2000): "El topónimo Hispal(is)", Philologia Hispalensis XIV: 181-190.

DE GRAEVE, M.-C. (1981): The ships of the ancient Near East (c. 2000-500 B.C.). Departement Oriëntalistiek, Leuven.

DELGADO, A. (2005): "La transformación de la arquitectura residencial en Andalucía occidental durante el Orientalizante: una lectura social", en S. Celestino y J. Jiménez (ed.), El Periodo Orientalizante (Anejos de Archivo Español de Arqueología XXXV): 585-594. CSIC, Mérida. 
DEL OLMO, G. (2004): “De los 1.000 y más dioses al Dios único. Cuantificación de los panteones orientales: de Egipto a Cartago", en A. González Blanco y otros (ed.), El mundo púnico. Religión, antropología y cultura material (Estudios Orientales 5-6): 19-32. Universidad de Murcia, Murcia.

DÍAZ TEJERA, A. (1982): Sevilla en los textos clásicos greco-latinos. Ayuntamiento de Sevilla, Sevilla.

DÍES CUSÍ, E. (1994): “Aspectos técnicos de las rutas comerciales fenicias en el Mediterráneo occidental (s. IX-VII a.C.)", Archivo de Prehistoria Levantina XXI: 311-336.

DÍES CUSÍ, E. (2004): "Los condicionantes técnicos de la navegación fenicia en el Mediterráneo oriental", en V. Peña y otros (ed.), La navegación fenicia. Tecnología naval y derroteros: 55-84. Centro de Estudios Fenicios y Púnicos, Madrid.

ESCACENA, J.L. (2005): "El templo y la ciudad. Que trata de cómo los fenicios poblaron Sevilla y su entorno", en A. Jiménez (ed.), La catedral en la ciudad (I). Sevilla, de Astarté a San Isidoro: 38-58. Aula Hernán Ruiz, Sevilla.

ESCACENA, J.L. (2006): "Allas el estrellero, o Darwin en las sacristías”, en J.L. Escacena y E. Ferrer (ed.), Entre Dios y los hombres: el sacerdocio en la Antigüedad (Spal Monografías VII): 103-156. Universidad de Sevilla, Sevilla.

ESCACENA, J.L. (e.p.): "Cantos de Sirena: la precolonización fenicia de Tartessos", en S. Celestino y otros (ed.), Contacto cultural entre el Mediterráneo y el Atlántico (siglos XII-VIII ANE): La Precolonización a debate. CSIC, Roma.

FERNÁNDEZ FLORES, A.; RODRÍGUEZ AZOGUE, A. (2005): "El complejo monumental del Carambolo Alto, Camas (Sevilla). Un santuario orientalizante en la paleodesembocadura del Guadalquivir", Trabajos de Prehistoria 62, 1: 111-138.

FERNÁNDEZ-MIRANDA, M. (1988): "La navegación fenicia hacia el lejano Occidente y el Estrecho de Gibraltar", Congreso Internacional «El Estrecho de Gibraltar»: 459-472. UNED, Madrid.

GAVALA, J. (1959): La geología de la costa y bahía de Cádiz y el poema "Ora Maritima”, de Avieno. Instituto Geológico y Minero de España, Madrid. Ed. facsímil en Cádiz, Diputación Provincial de Cádiz, 1992.

GREENHILL, B. (1976): Archaeology of the boat. Adam and Charles Black, London.

GUERRERO, V.M. (1993): Navíos y navegantes en las rutas de Baleares durante la Prehistoria. El Tall, Palma de Mallorca.

GUERRERO, V.M. (1998): "Los mercantes feniciopúnicos en la documentación literaria, iconográfica y arqueológica", en B. Costa y J. H. Fernández, Rutas, navíos y puertos fenicio-púnicos (XI Jornadas de Arqueología Fenicio-Púnica): 61-103. Museo de Ibiza y Formentera, Ibiza.

GUERRERO, V.M. (2004): "Las islas Baleares en los derroteros del Mediterráneo central y occidental”, en V. Peña y otros (ed.), La navegación fenicia. Tecnología naval y derroteros: 85-133. Centro de Estudios Fenicios y Púnicos, Madrid.

GUIBAL, F.; POMEY, P. (2003): “Timber supply and ancient naval architecture", en C. Beltrame (ed.), Boats, ships and shipyards: 35-41. Oxbow Books, Oxford.

HORNELL, J. (1946): "The role of birds in early navigation", Antiquity 20: 142-149.

HORNUNG, E. (1999): El Uno y los Múltiples. Concepciones egipcias de la divinidad. Trotta, Madrid.

IZQUIERDO, R.; ESCACENA, J.L. (1998): "Sobre El Carambolo: «La trompeta de Argantonio»", Archivo Español de Arqueología 71: 27-36.

KARAGEORGHIS, V. (2004): Chipre. Encrucijada del Mediterráneo oriental 1600-500 a.C. Bellaterra, Barcelona.

LIPINSKI, E. (1984): "Vestiges phéniciens d'Andalousie", Orientalia Lovaniensia Periodica 15: 81-132.

LIVERANI. M. (2004): Más allá de la Biblia. Historia antigua de Israel. Crítica, Barcelona.

LULL, J. (2004): La astronomía en el antiguo Egipto. Universidad de Valencia, Valencia.

LUZÓN, J.M. (1988): "Los hippoi gaditanos", Congreso Internacional «El Estrecho de Gibraltar»: 445458. UNED, Madrid.

LUZÓN, J.M.; COÍN, L. (1986): "La navegación preastronómica en la Antigüedad: utilización de pájaros en la orientación náutica", Lvcentvm V: 65-85.

MARTÍN, D.; CAMALICH, M.D. (1982): "La "cerámica simbólica" y su problemática (aproximación a través de los materiales de la colección L. Siret)", Cuadernos de Prehistoria de la Universidad de Granada 7: 267-306.

MAZZA, F. (1988): "L'imagine dei Fenici nel mondo antico", en S. Moscati (dir.), I Fenici: 548-567. Fabbri, Milano.

MEDAS, S. (2004): “L'orientamento astronomico: aspetti tecnici della navigazione fenicio-punica tra retorica e realtà", en V. Peña y otros (ed.), La navegación fenicia. Tecnología naval y derroteros: 4353. Centro de Estudios Fenicios y Púnicos, Madrid.

MELLER, H. (2004): "El disco celeste de Nebra", Investigación y Ciencia 335: 70-75.

MENANTEAU, L. (1982): Les Marismas du Guadalquivir, exemple de transformation d'un paysage alluvial au cours du Quaternaire récent. Université de Paris-Sorbonne, Paris.

MOLINA, F. (2005): Guía del yacimiento arqueológico. Los Millares. Junta de Andalucía, s.1. 
NEGUERUELA, I.; PINEDO, J.; GÓMEZ, M.; MIÑANO, A.; ARELLANO, I.; BARBA, J.S. (2000): "Descubrimiento de dos barcos fenicios en Mazarrón (Murcia)", en M.E. Aubet y M. Barthélemy (ed.), IV Congreso Internacional de Estudios Fenicios y Púnicos, vol. IV: 1671-1679. Universidad de Cádiz, Cádiz.

NEGUERUELA, I. (2004): "Hacia la comprensión de la construcción naval fenicia según el barco "Mazarrón-2" del siglo VII a.C.", en V. Peña y otros (ed.), La navegación fenicia. Tecnología naval y derroteros: 227-278. Centro de Estudios Fenicios y Púnicos, Madrid.

PARODI, M.J. (2001): Ríos y lagunas de Hispania como vías de comunicación. La navegación interior en la Hispania romana. Gráficas Sol, Écija.

RODRÍGUEZ AZOGUE, A.; FERNÁNDEZ FLORES, A. (2005): "El santuario orientalizante del cerro del Carambolo, Camas (Sevilla). Avance de los resultados de la segunda fase de la intervención", en S. Celestino y J. Jiménez (ed.), El Periodo Orientalizante (Anejos de Archivo Español de Arqueología XXXV): 863-871. CSIC, Mérida.

ROUGÉ, J. (1975): La marine dans l'Antiquité. Presses Universitaires de France, Paris.

RUIZ CABRERO, L.A. (2007): "La marina de los fenicios, de la creencia en la vida a las naves de la muerte", Homenaje al Profesor Juan Cascajero (Extra de Gerión): 93-121.

RUIZ DE ARBULO, J. (1998): "Rutas marítimas y tradiciones náuticas. Cuestiones en torno a las navegaciones tirias al Mediterráneo occidental”, en B. Costa y J. H. Fernández, Rutas, navios y puertos fenicio-púnicos (XI Jornadas de Arqueología Fenicio-Púnica): 25-48. Museo de Ibiza y Formentera, Ibiza.
RUIZ DE ARBULO, J. (2006): “Cuestiones económicas y sociales en torno a los santuarios de Isis y Serapis. La ofrenda de Numas en Emporion y el Serapeo de Ostia”, en J.L. Escacena y E. Ferrer (ed.), Entre Dios y los hombres: el sacerdocio en la Antigüedad (Spal Monografías VII): 197-227. Universidad de Sevilla, Sevilla.

SCANDONE, G. (1991): "Hathor Signora di Biblo e la Baalat Gebal", Atti II Congreso Internazionale di Studi Fenici e Punici I: 401-406. Consiglio Nazionale delle Ricerche, Roma.

SCHULTEN, A. (1955): Fontes Hispaniae Antiquae I. Universidad de Barcelona, Barcelona.

STAGER, L.E. (2004): "Dos pecios fenicios en alta mar de la costa norte del Sinaî", en V. Peña y otros (ed.), La navegación fenicia. Tecnología naval y derroteros: 179-195. Centro de Estudios Fenicios y Púnicos, Madrid.

TORR, C. (1964): Ancient ships. Argonaut, Inc., Publishers, Chicago.

TORRES, M. (2002): Tartessos (Bibliotheca Archaeologica Hispana 14). Real Academia de la Historia, Madrid.

TORRES, M. (2004): "Un fragmento de vaso askoide nurágico del fondo de cabaña del Carambolo", Complutum 15: 45-50.

VITA, J.P. (2000): "Los antecedentes de la marina fenicia: barcos en Ugarit", en M.E. Aubet y M. Barthélemy (ed.), IV Congreso Internacional de Estudios Fenicios y Púnicos, vol. I: 281-288. Universidad de Cádiz, Cádiz.

WESTERBERG, K. (1983): Cypriote ships from the Bronze Age to c. 500 BC (Studies in Mediterranean Archaeology 22). P. Åströms, Gothenburg.

Recibido el 17-01-07 Aceptado el 12-03-07 